Zhanguo Zhu, Feng Chu, Alexandre Dolgui, Chengbin Chu, Wei Zhou \& Selwyn Piramuthu. Recent advances and opportunities in sustainable food supply chain: a model-oriented review, Volume 56, 2018 - Issue 1, Pages

5700-5722. Received 06 May 2017, Accepted 05 Dec 2017, Published online: 31 Jan 2018

\title{
Recent Advances and Opportunities in Sustainable Food Supply Chain: A Model-oriented Review
}

\author{
Zhanguo Zhu ${ }^{a, b}$, Feng Chu ${ }^{\text {b,c }}$, Alexandre Dolgui ${ }^{f}$, Chengbin Chu ${ }^{d, e}, 1$, \\ Wei Zhou ${ }^{g}$, Selwyn Piramuthu ${ }^{\mathrm{h}}$
}

\author{
aCollege of Economics and Management, Nanjing Agricultural University, Nanjing, 210095, P.R. China \\ ${ }^{\mathrm{b}}$ Laboratoire d'informatique, biologie inte'grative et syste 'mes complexes (IBISC), Univ Evry, University of Paris Saclay, 91000 \\ Evry, France \\ 'Management Engineering Research Center, Xinhua University, Chengdu, 610039, P.R. China \\ dESIEE Paris, 2 boulevard Blaise Pascal - BP 99, 93162 Noisy-le-Grand Cedex, France eSchool of \\ Management, Northwestern Polytechnical University, Xian, 710072, P. R. China \\ fIMT Atlantique, LS2N, UMR CNRS 6004, La Chantrerie, 4, rue Alfred Kastler - B.P. 20722, F-44307 Nantes Cedex 3, France \\ gInformation \& Operations Management, ESCP Europe, Paris, France \\ hInformation Systems \& Operations Management, University of Florida, Gainesville, FL, USA
}

\begin{abstract}
Faced with the challenges associated with sustainably feeding the world's growing population, the food industry is increasingly relying on operations research $(\mathrm{OR})$ techniques to achieve economic, environmental, and social sustainability. It is therefore important to understand the context-specific model-oriented applications of OR techniques in the sustainable food supply chain (SFSC) domain. While existing food supply chain (FSC) reviews provide an excellent basis for this process, the explicit consideration of sustainability from a model-oriented perspective along with a structured outline of relevant SFSC research techniques are missing in extant literature. We attempt to fill this gap by reviewing 83 related scientific journal publications that utilize mathematical modeling techniques to address issues in SFSC. To this end, we first identify the salient dimensions that include economic, environmental, and social issues in SFSC. We then review the models and methods that use these dimensions to solve issues that arise in SFSC. We identify some of the main challenges in analytical modeling of SFSC as well as future
\end{abstract} research directions.

Key words: Sustainable supply chain; Food industry; Operations research; Models; Review

1 Corresponding author.

Email addresses: Zhanguo.Zhu@ibisc.univ-evry.fr (Zhanguo Zhu), feng.chu@univ-evry.fr (Feng Chu), alexandre.dolgui@imt-atlantique.fr (Alexandre Dolgui), chengbin.chu@ecp.fr (Chengbin Chu), wzhou@escpeurope.eu (Wei Zhou), selwyn@ufl.edu (Selwyn Piramuthu). 
1 Introduction

The food and beverage industry, with direct impacts on the daily lives of the entire society, plays a vital role in both regional and global economies. The EU (European Union) food and beverage industry, for example, accounted for almost $8 \%$ of EU Gross Domestic Product (GDP) [44]. China's food industry accounted for $15.8 \%$ of its GDP in 2010, and France contributed $10.7 \%$ in $2011[45]$. Increasing demand for food, fueled primarily by growth in population and wealth, not only leads to higher prices and increased market volatility (Dobbs et al., 2011 [36]) but also places a higher burden on scarce natural resources such as clean water, land, and energy (Dobbs et al., 2011; Parfittet al., 2011[77]). It poses a major threat to sustainable development (Brundtland, 1987[102]) and urgently calls for new modes of food supply chain (FSC) that develops a sustainable balance through the triple bottom line by simultaneously considering economic, environmental, and social issues (Elkington(1998) [40]).

Involving all collaborating partners from farmers, food processors, distributers and retailers, today's global FSC provides end consumers with a wide variety of food options that include fresh produce, meat, and a large variety of processed food products. Food products can be categorized as two main types: 1. "fresh" agricultural produce (such as fresh vegetables and fruits) and 2. "processed" food products (such as snacks, desserts, and canned food) [105]. The management of food supply chains of both types are generally very different from that of industrial supply chain because of food products' unique properties such as perishability, strict governmental regulations on food safety, consumers' high variation on tastes and processes, and consequential operational constraints on their storage, processing, and distribution. Today's FSC faces issues such as high energy consumption, greenhouse gas (GHG) emissions, and other economic and social concerns. First of all, energy plays a large role in the life cycle of a food product. Food-related energy usage as a percentage of the national energy budget grew from $14.4 \%$ in 2002 to $15.7 \%$ in 2007 in the U.S. (USDA, 2010 [23]). Energy consumption for temperature control is necessary to guarantee food quality and safety. Temperature control can greatly affect food quality by influencing the level of food deterioration over time (e.g., spoilage of perishable products) and product safety by influencing the growth of potentially harmful bacteria (e.g., Salmonella and Escherichia coli). Secondly, FSC is often accompanied by GHG emissions. A regional analysis in Europe finds that food accounts for 31\% of the EU-25s total GHG impact (European Commission, 2006 [39]). Thirdly, food products with short shelf 
lives require a more efficient distribution system due to their high quality-deterioration risk. Lastly, social responsibility initiatives such as fair trade and localism may affect the way any given FSC operates.

Sustainable food production is becoming popular due to increased awareness and visibility of the environmental, economic and social issues in the general FSC. As van der Vorst et al. (2009) [106] has observed, consumers place higher expectations on food sustainability with specific emphasis on facets related to energy, emissions, food quality and safety, and social responsibility. This trend has profoundly changed the configuration and mode of current food supply systems, resulting in more efficient operational technologies that are designed to optimize sustainable food supply chains. These newly introduced technologies have clearly resulted in corresponding sustainable benefits with respect to the three main dimensions (economic, environmental, and social). Consumers' high expectations for sustainably produced food along with the recent advances in OR techniques have stimulated/facilitated companies in the food supply chain to pursue more effective model-oriented methods to explicitly address those unique problems in SFSC. Consequently, the application of OR-based methods, especially model-oriented methods in sustainable food supply chain, have increased in recent years. To the best of our knowledge, existing published reviews on food supply chain models have not explicitly considered sustainability issues. We attempt to fill this gap, and present a comprehensive review of published model-oriented papers on sustainable food supply chain. Based on our review, we identify potential future research directions along with associated modeling techniques to help facilitate progress and thereby benefit both the industry and researchers in this important domain.

The rest of this paper is organized as follows. In Section 2, we provide a brief overview of previous literature reviews related to this work and our contributions. In Section 3, we introduce the methodological approach undertaken. In Section 4, we review and evaluate the main research problems of SFSC in existing published literature and relevant models that have been used to solve these problems. We discuss challenges, future research directions, and opportunities in Section 5. We conclude with a brief discussion in Section 6.

\section{Existing Reviews \& Our Contribution}

Related extant published literature reviews can be placed in three categories: 1) sustainable supply chain (SSC), 2) food supply chain (FSC), and 3) sustainable food supply chain (SFSC), as in Table 1. The first category includes two review papers that address general SSC issues and creates a foundation for the analysis of SFSC. For example, we apply the sustainability dimension framework that includes economic, environmental, and social aspects, and modeling dimension for SSC as identified by Seuring (2013)[87] and Brandenburg et al. (2014)[21] to help analyze 
SFSC issues, disregarding the application domain of prior SSC studies. The second category gathers nine review papers on FSC, but the sustainability aspect is not considered as a main characteristic in these papers. Almost all of these review papers discuss the research contribution of FSC modeling methods, such as one stage of crop production (Glen (1987)[47], Lowe and Preckel (2004)[65], Zhang and Wilhelm (2009) [116], Kusumastuti et al. (2016)[60]) with the intent to provide insights for growers, and multiple stages across the chain (Ahumada and Villalobos (2009)[5], Rodrguez et al. (2014)[82], Soto-Silva et al. (2015)[93], and Borodin et al. (2016)[17]) aiming to stimulate interest in food processing and distribution, among others. An exclusion is that of Shukla and Jharkharia (2012)[90], who review papers involving not only analytical modeling but also empirical studies. The third category includes three review papers on SFSC (Akkerman et al. (2010) [8], Li et al. (2014)[64], and Beske et al. (2014)[15]), however all of them are different from our current work. Akkerman et al. (2010)[8] review papers on food quality, food safety, and sustainability in food distribution management and observe that very limited attention in literature is paid to designing sustainable food distribution network. Their work focuses on food distribution networks and considers papers that were published before 2010, with most of the considered papers not explicitly modeling sustainability issues. In contrast, all 83 papers that we consider deal with sustainability as a main characteristic of the problem under study, and only one reviewed paper (Van der Vorst et al. 2009[106]) appears in both Akkerman et al. (2010)[8] and our work. Beske et al. (2014)[15] consider SSCM practices and dynamic capabilities (DC) in the food industry and observe that sustainability practices and DCs in the supply chain are used among others to enhance traceability and tracking and to fulfill customer demands in the food industry. Moreover, modeling methodology plays a subordinate role in the papers that were reviewed in Beske et al. (2014)[15]. Their main focus is limited to DC and the stages after farming, which ignores key issues such as agricultural production. Li et al. (2014)[64] provide a detailed editorial introduction on existing and future challenges in research on SFSC management for a special issue on SFSC. Since this is not a formal literature review, it lacks a comprehensive analysis of the agricultural production stage of the food supply chain.

All considered, no prior published literature review has focused on the model-oriented perspective of SFSC. However, the various mathematical methodologies that have been used to solve the environmental, social and economic problems in SFSC are uniquely positioned and deserve a systematic review that could help pave the way for future research. We are therefore motivated to fill this gap by reviewing research problems in SFSC from a model-oriented perspective, as the last row of Table 1, and covering the entire FSC.

Table 1

Previous Literature Reviews

\begin{tabular}{|c|c|c|}
\hline Type of SC & Article & Approach focusTime horizon \\
\hline
\end{tabular}




\begin{tabular}{|c|c|c|c|c|c|c|}
\hline SSC & Brandenburg et al. (2014)[21] & Modeling & 1994-2012 & Entire SC & 134 & EJOR \\
\hline SSC & Seuring (2013)[87] & Modeling & $1997-2010$ & Entire SC & 36 & DSS \\
\hline FSC & Borodin et al. (2016)[17] & Modeling & Until 2015 & Unspecified & 111 & EJOR \\
\hline FSC & Soto-Silva et al. (2015)[93] & Modeling & $1976-2015$ & Fresh fruit & 28 & EJOR \\
\hline FSC & Kusumastuti et al. (2016)[60] & Modeling & $1983-2013$ & Harvesting/ processing & 76 & IJPE \\
\hline FSC & Glen (1987)[47] & Modeling & Until 1987 & Agri-production & - & OR \\
\hline FSC & Rodrguez et al. (2014)[82] & Modeling & Until 2013 & Pork & 31 & AOR \\
\hline FSC & Shukla and Jharkharia (2012)[90] & General & $1991-2011$ & Agri-fresh produce & 86 & IJOPM \\
\hline FSC & Zhang and Wilhelm (2009) [116] & Modeling & Until 2009 & Specialty crops & 27 & AOR \\
\hline FSC & Ahumada and Villalobos (2009)[5] & Modeling & Until 2007 & Unspecified & - & EJOR \\
\hline FSC & Lowe and Preckel (2004)[65] & Modeling & Until 2004 & Agribusiness & $<34$ & MSOM \\
\hline SFSC & Akkerman et al. (2010) [8] & Modeling & Until 2010 & Distribution network & - & OR-Spec \\
\hline SFSC & Li et al. (2014)[64] & General & Until 2014 & Without agri-production & - & IJPE \\
\hline SFSC & Beske et al. (2014)[15] & Not modeling & $2002-2011$ & Dynamic capabilities & 52 & IJPE \\
\hline SFSC & Current study & Modeling & Until 2017 & Entire FSC & 83 & - \\
\hline
\end{tabular}

3 Material Selection

To obtain a synthesis of published literature, we collected relevant papers by first performing online literature search in main electronic bibliographical sources (web of science, science direct, etc.) using phrases such as "sustainable(ility)" and "food (agri-food) supply chain". Then "environment(al)", "society(al)", "agriculture(al) supply chain", "vegetable supply chain", "meat supply chain”, "dairy (milk) supply chain", "fruit supply chain", "food product", and "agri-fresh produce". Invariably, our search results included many irrelevant papers. Second, we restricted the papers from the above collection according to the following rules.

(1) Papers written in English and published in peer-reviewed journals.

(2) Because the focus of this review is on model-oriented methods in SFSC, only those with quantitative models are retained. Therefore, the selected papers are limited to the field of management science, operations research, decision science, food technology and engineering, agricultural economics, mathematics, and computer science.

We found very few model-oriented papers on SFSC before the year 2000. Therefore, most of the selected papers were published during the period from 2000 to 2016 .

In total, we selected 83 papers. The distribution of papers over journals (Fig. 1) shows that the papers are from journals in operations management (about 90\%) and food/agricultural economics (about 10\%). Moreover, about 70\% of the papers appear in four specific journals including International Journal of Production Research, In- 


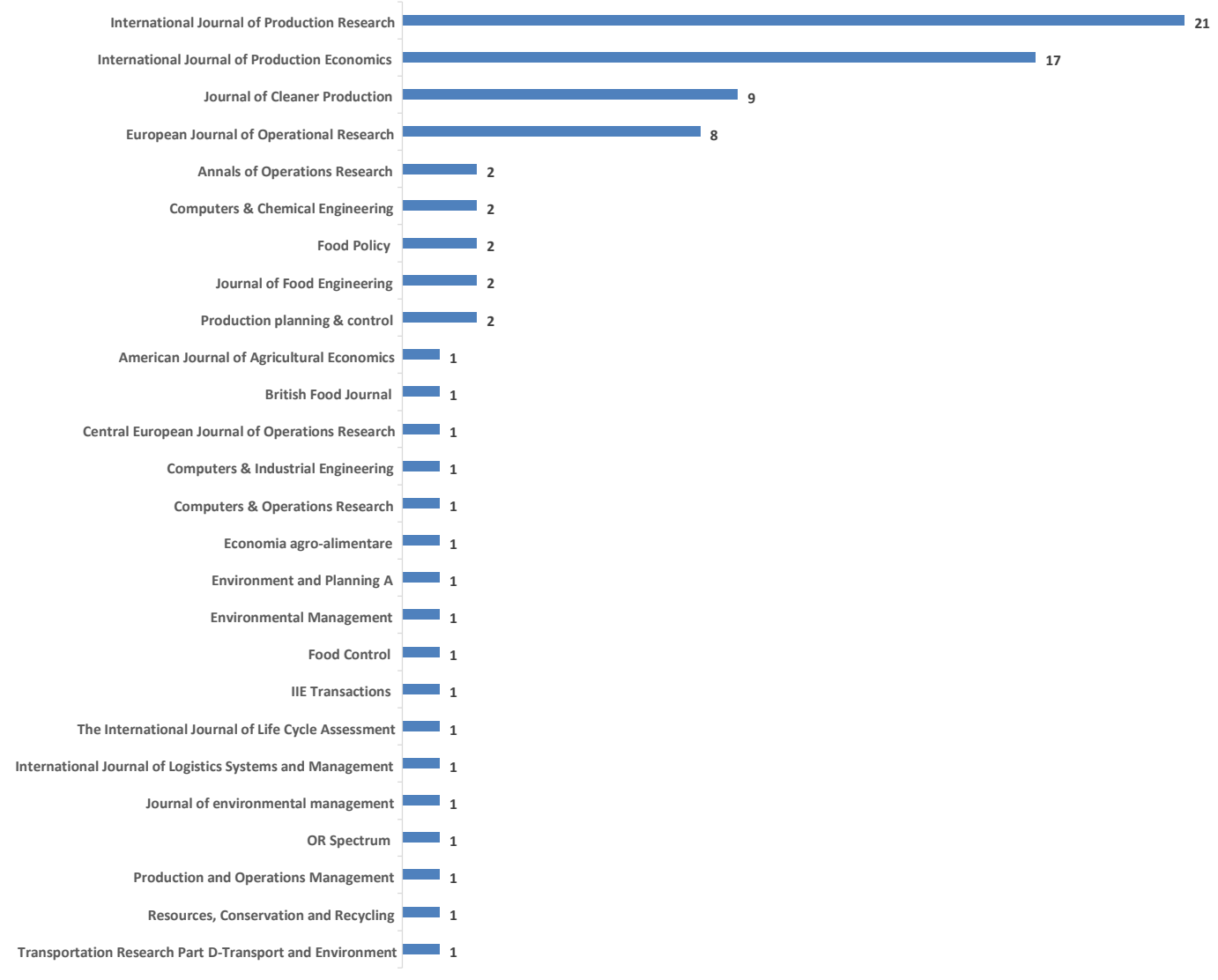

Fig. 1. Number of Papers Published in Different Journals

ternational Journal of Production Economics, Journal of Cleaner Production, European Journal of Operational Research, showing that a majority of the reviewed papers address the SFSC issues from an operations perspective.

From the 83 selected papers, the annual publication frequency shows steady growth since 2010 . The number of relevant papers was less than two per year from 2002 to 2010 and more than 10 per year from 2014 to 2016. There are 26 papers in just one year (2016). The increasing number of published papers in this domain indicates the increasing attention attracted by SFSC in recent years. Unlike FSC and SSC, model-based SFSC research is a relatively new field (Borodin et al. (2016)[17], and Ahumada and Villalobos (2009)[5]).

\section{Evaluation of SFSC Research}

As in Fig. 2, a sustainable food supply chain involves different segments that collaborate to provide end consumers with plant-based and/or animal-based products comprising agricultural production, food processing, distributing, retailing, consuming, etc. that correspond to actors such as farmers, processors, food distributors, retailers, and consumers. While each actor in the sustainable food supply chain uses natural resources that 
include water, soil, air, and energy as input, the ideal goal is to create a reverse food supply chain through a feedback loop throughout the procedure. Through its production and consumption activities, SFSC generates major environmental, social and economic issues (Ahumada and Villalobos (2009)[5], Soto-Silva et al. (2015)[93], and Brandenburg et al. (2014)[21]), as in Table 2. To solve optimization problems that are associated with sustainability including economic, environmental and social parameters, modeling approaches and solution methods are often used to draw insights and to reach conclusions.

In general, the major environmental issues include GHG emission, energy consumption, ecological issues, and natural resources consumption including water and land, etc., as in Table 3. The main social issues of SFSC include food safety, animal welfare, fairness, and employment/training, as in Table 4, which are very different from those of general supply chain (Brandenburg et al. (2014)[21]). The economic issues are often linked with the environmental and social issues, including profitability, efficiency, pricing on quality, consumer preferences, cost optimization and revenue management. Existing studies that aim to solve these three major issues very often utilize quantitative models, including life cycle assessment (LCA), game theory, linear programming (LP), stochastic programming (SP), mixed integer programming (MIP), non-linear programming (NLP), mixed integer non-linear programming model (MINLP), multi-objective programming (MOP), simulation, and corresponding solution methods. Moreover, SFSC is very context-based due to the variability of food system in defferent countries.

Therefore, we evaluate existing SFSC research in more detail based on the following dimensions: sustainability, SC actors, modeling approaches and solution methods, the application in different countries, and types of food products.

\subsection{Sustainability}

\subsubsection{The dimensions of sustainability}

In our considered list of papers, 62 papers spend much effort on environment issues while only 28 papers involve social isues, as in Table 2. Most SFSC studies have multiple dimensions with environmental and economic dimensions or social and economic ones, accounting for near $80 \%$ of the reviewed papers. Among them, fortyfour 


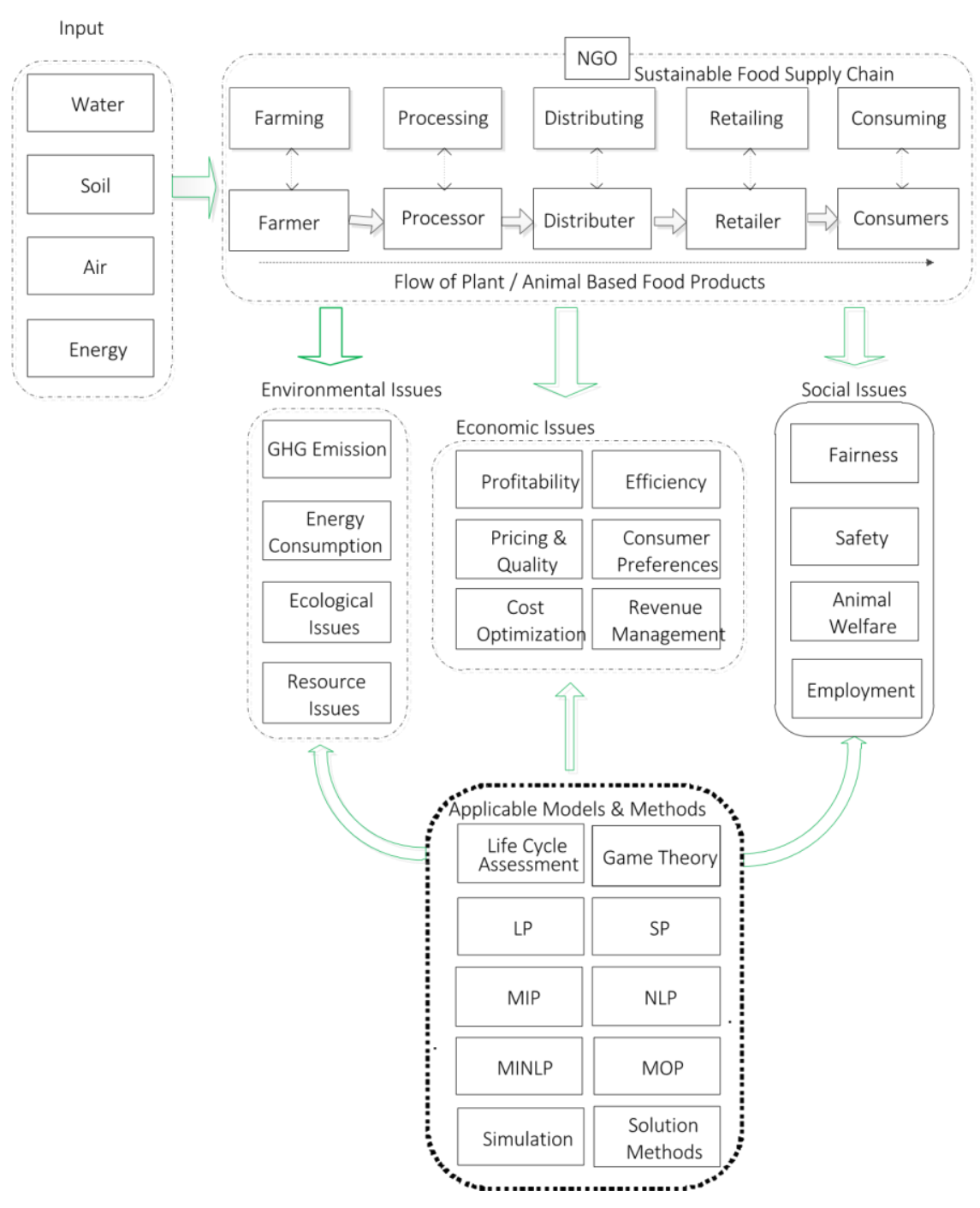

Fig. 2. Framework of SFSC Research

papers cover environmental-economic issues, almost triple that on social-economic issues. Although simultaneous decision in three dimensions of environmental, social, and economic issues is more realistic due to the interdependencies among these dimensions, the number of SFSC models focusing on the interplay of all three dimensions remain small. However, they receive more attention than general SSC since there are only two papers integrating all three dimensions of sustainability and no paper that exclusively addresses social issues for general sustainable supply chain claimed by Seuring (2013) [87] in a review of modeling approaches for general sustainable supply chain. A possible reason may be consumers' increasing concerns on typical issues in FSC such as food safety, animal welfare, and food donation operations, etc. that belong to the social metric. The economic issues with respect to total cost or profit are closely linked to the environmental and social issues in SFSC, therefore, we only analyze the environment and social problems in the following subsections. 


\begin{tabular}{|c|c|c|c|c|c|}
\hline Article & Env & Soc & Env+Soc+Eco & Soc+Eco & Env+Eco \\
\hline Jones (2002) [56] & - & - & - & - & - \\
\hline Sonesson and Berlin (2003) [92] & - & - & - & - & - \\
\hline Roy et al. (2008)[85] & - & - & - & - & - \\
\hline Vanek and Sun (2008)[107] & $\bullet$ & - & - & - & - \\
\hline Virtanen et al. (2011)[108] & - & - & - & - & - \\
\hline Meneses et al.(2012)[70] & $\bullet$ & - & - & - & - \\
\hline Abeliotis et al. (2013)[2] & • & - & - & - & - \\
\hline Webb et al. (2013)[112] & - & - & - & - & - \\
\hline Alfandari et al. (2014)[9] & - & - & - & - & - \\
\hline Tasca et al. (2016)[99] & • & - & - & - & - \\
\hline Kulak et al. (2016)[59] & - & - & - & - & - \\
\hline Van der Gaag et al. (2004)[104] & - & $\bullet$ & - & - & - \\
\hline Manning et al. (2006)[68] & - & - & - & - & - \\
\hline Stringer and Hall (2007)[97] & - & • & - & - & - \\
\hline Wang et al. (2012)[111] & - & $\bullet$ & - & - & - \\
\hline Chebolu and Gaukler (2015)[25] & - & - & - & - & - \\
\hline Davis et al. (2016)[33] & - & $\bullet$ & - & - & - \\
\hline Krieter (2002)[58] & - & - & $\bullet$ & - & - \\
\hline Oglethorpe(2010)[75] & - & - & $\bullet$ & - & - \\
\hline Yakovleva et al. (2012)[114] & - & - & - & - & - \\
\hline Azadnia et al. (2014)[12] & - & - & • & - & - \\
\hline Lee and Tongarlak (2016)[62] & - & - & $\bullet$ & - & - \\
\hline Miret et al. (2016)[71] & - & - & $\bullet$ & - & - \\
\hline Tang et al. (2016)[98] & - & - & • & - & - \\
\hline Broek et al. (2006)[22] & - & - & - & $\bullet$ & - \\
\hline Schutz et al. (2008)[86]" & - & - & - & - & - \\
\hline Wang et al. (2009)[110] & - & - & - & • & - \\
\hline Akkerman et al. (2010)[7] & - & - & - & $\bullet$ & - \\
\hline Resende-Filho and Hurley 2012[80] & - & - & - & $\bullet$ & - \\
\hline Chen et al. (2013)[26] & - & - & - & - & - \\
\hline Mohan et al. (2013)[72] & - & - & - & - & - \\
\hline Piramuthu et al. (2013)[78] & - & - & - & $\bullet$ & - \\
\hline Chen et al. (2014)[27] & - & - & - & $\bullet$ & - \\
\hline Ting et al. $(2014)[100]$ & - & - & - & $\bullet$ & - \\
\hline Dai et al. (2015)[32] & - & - & - & - & - \\
\hline Ghezavati et al. (2015)[46] & - & - & - & $\bullet$ & - \\
\hline Orgut et al. (2016)[76] & - & - & - & $\bullet$ & - \\
\hline Banasik et al. (2016a)[13] & - & - & - & $\bullet$ & - \\
\hline Wang et al. (2016)[109] & - & - & - & • & - \\
\hline Others (44 papers) & - & - & - & - & - \\
\hline
\end{tabular}




\subsubsection{Main Environmental Research Problems}

The specific environmental issues in SFSC involve the GHG emission, energy consumption, ecological issues, natural resources (water/land), other issues such as agricultural production related pollution as well as the use of fertilizers and pesticides, as in Table 3.

As a key aspect among all environmental issues in SFSC, GHG emission has attracted the most attention. Many studies investigate and model the GHG emission generated in the food distribution system in the similar way as the studies on general SSC (Govindan et al. (2014)[49], Soysal et al. (2014)[94], Validi et al. (2014)[103], Bortolini et al. (2016)[18], etc). They consider the energy consumption related GHG emission from food distribution but ignore the GHG emission from refrigerant leakage into the environment and from agricultural production. Most energy consumption related studies involve GHG emission since GHG emission can usually be calculated based on energy consumption., e.g., Van der Vorst et al. (2009)[106], Cholette (2011)[29], Meneses et al. (2012)[70], and Soysal et al. (2015)[95].

Facing the challenge of an intensive use of pesticides, synthetic fertilizers, and other polluting resources in conventional agricultural system, ecologically-based agricultural production gains increasing concerns. However, the related studies are very limited. Only three papers deal with it (dos Santos et al. (2010)[37], Costa et al. (2011)[31], Alfandari et al. (2015)[9]) and all of them belong to the class of crop rotation planning problems. For example, dos Santos et al. (2010)[37] analyze a vegetable crop rotation planning problem that is subject to ecology-based constraints, e.g., the interdiction of certain crop successions as well as the regular insertion of fallow and the use of green manure.

Although the natural resources such as water/land play significant role in SFSC, especially the stage of agricultural production, the environmental effects of water/land use are addressed relatively little. Only eight papers investigate them and many of them are analyzed with LCA. For example, Del Borghi et al. (2014)[34] use LCA to discuss the environmental impacts of 13 tomato-based products produced in Italy, where water consumption and land occupation are both considered. Krieter (2002)[58] investigates a vertically integrated production system for pig farming that involves environmental aspects measured by nitrogen $(N)$ and phosphorus $(P)$ excretion. In a study analyzing the sustainability of agri-food supply chain (endive) through LCA, the intensity of fertilizer and pesticide use are considered as important aspects to measure environmental sustainability by Tasca et al. 2016[99]. Sgarbossa and Russo (2016)[88] develop a new sustainable model of closed-loop food supply chain using and recovering slaughtering waste from meat processing to realize food waste reduction. 
Other important aspects of environmental effects in SFSC due to the characteristics of food production include food waste reduction, biological factors (Abedi and Zhu (2016)[1]), meteorological conditions (Borodin et al. (2014)[16]), and food waste (Sgarbossa-Russo (2016)[88]), etc.

\subsubsection{Main Social Research Problems}

The differences with respect to social dimension in SFSC and general SSC are readily observed. Most of the social issues in SFSC are typical such as food safety, animal welfare, and food donation, as in Table 4. Food safety has been investigated the most, accounting for nearly half of the reviewed papers involving social issues. Food recall caused by food product contamination is particularly critical for food safety. Almost all these studies discuss how to model contaminated food product recall in food supply networks. On one hand, many papers are concerned with minimizing food product recalls, risk transmission, etc. using mathematical programming optimization models. Dupuy et al. (2005)[38] propose a mixed integer linear programming model to minimize the quantity of recalls in a sausage manufacturing process. Rong and Grunow (2010)[84] present a multi-period production and distribution planning model to improve food safety based on the concept of chain dispersion and the risk attitudes of the decision maker. On the other hand, with analytical models, some papers provide general insights on the liability and interests for different actors in food supply networks with respect to food safety issues. For example, Piramuthu et al. (2013)[78] consider the contaminated perishable food product recall problem based on RFID-generated traceability. In their work, recall as well as liability allocation among different actors in the supply network are studied.

Animal welfare that includes humane approaches to handling, housing, transport, and slaughter [66] is another important social issue that has received increasing public concerns in recent years, but studies from the perspective of modeling are few. Although four papers discuss animal welfare, only one paper integrates it in a mathematical model. Broek et al. (2006)[22] address animal welfare by incorporating restriction on the livestock transport in EU as a constraint in a mathematical programming model.

Food donation significantly contributes to relieve food insecurity that occurs when the individual's access to safe and nutritious food for healthy life are limited. Food donation-driven supply chains place particular emphasis on the role of food banks, and are very different from that of general commercial supply chains due to their nonprofit nature (Dai et al. (2015)[32]). From our collected papers, only two papers have that focus. Dai et al. (2015)[32] analyze supply uncertainty associated with food donations and propose predictive models to estimate the quantity 
Main SFSC Environmental Research Problems

Article

GHG emission Energy consumption Ecological issues Resource(Water/Land, etc.) Others

\begin{tabular}{|c|c|c|c|c|c|}
\hline Krieter (2002)[58] & - & - & - & - & - \\
\hline Jones (2002) [56] & • & - & - & - & - \\
\hline Sonesson and Berlin (2003) [92] & - & - & - & - & - \\
\hline Roy et al. (2008)[85] & - & - & - & - & - \\
\hline Vanek and Sun (2008)[107] & - & - & - & - & - \\
\hline Van der Vorst et al. (2009)[106] & - & - & - & - & - \\
\hline dos Santos et al. (2010)[37] & - & - & - & - & - \\
\hline Oglethorpe (2010)[75] & - & - & - & - & - \\
\hline Costa et al. (2011)[31] & - & - & - & - & - \\
\hline Cholette (2011)[29] & - & - & & - & - \\
\hline Nicholson et al. (2011)[74] & - & - & - & - & - \\
\hline Rong et al. (2011)[83] & - & - & - & - & - \\
\hline Virtanen et al. (2011)[108] & - & - & - & - & - \\
\hline Amorim et al. (2012)[10] & - & - & - & - & - \\
\hline Meneses et al. (2012)[70] & - & - & - & - & - \\
\hline Zanoni and Zavanella (2012)[115] & - & - & - & - & - \\
\hline Yakovleva et al. (2012)[114] & - & - & - & - & - \\
\hline Diabat et al. (2012)[35] & - & - & - & - & - \\
\hline Hasani et al. (2012)[53] & - & - & - & - & - \\
\hline Abeliotis et al. (2013)[2] & - & - & - & - & - \\
\hline Webb et al. (2013)[112] & • & - & - & - & - \\
\hline Accorsi et al. (2014)[3] & - & - & - & - & - \\
\hline Alfandari et al. (2015)[9] & - & - & - & - & - \\
\hline Atallah et al. (2014)[11] & - & - & - & - & - \\
\hline Azadnia et al. (2015)[12] & - & - & - & - & - \\
\hline Borodin et al. (2014)[16] & - & - & - & - & - \\
\hline Del Borghi et al. (2014)[34] & - & - & - & - & - \\
\hline Govindan et al. (2014)[49] & - & - & - & - & - \\
\hline Manfredi and Vignali (2014)[67] & - & - & - & - & - \\
\hline Soysal et al. (2014)[94] & - & - & - & - & - \\
\hline Validi et al. (2014)[103] & - & - & - & - & - \\
\hline Chen and Hsu (2015)[28] & - & - & - & - & - \\
\hline Gonela et al. (2015)[48] & - & - & - & - & - \\
\hline Li and Wang (2015)[63] & - & - & - & - & - \\
\hline Meneghetti-Monti et al. (2015)[69] & - & - & - & - & - \\
\hline Soysal et al. (2015)[95] & - & • & - & - & - \\
\hline Abedi and Zhu (2016)[1] & - & - & - & - & • \\
\hline Accorsi et al. (2016)[4] & - & • & - & - & - \\
\hline Ai et al. (2016)[6] & - & - & - & - & - \\
\hline Banasik et al. (2016a)[13] & - & - & - & - & - \\
\hline Banasik et al. (2016b)[14] & - & - & - & - & - \\
\hline Bortolini et al. (2016)[19] & - & - & - & - & - \\
\hline Bortolini et al. (2016)[18] & - & - & - & - & - \\
\hline Bozorgi (2016)[20] & - & - & - & - & - \\
\hline Chang et al. (2016)[24] & - & - & - & - & - \\
\hline Colicchia et al. (2016)[30] & - & - & - & - & - \\
\hline Guo et al. (2016)[50] & - & - & - & - & - \\
\hline
\end{tabular}


Hu et al. (2016)[54]

Ivanov et al. (2016)[55]

of in-kind food donations. They also discuss the relationships among forecast accuracy, donation behavior, and data uncertainty, and provide insights on how to affect operational decisions of the food bank. Orgut et al. (2016)[76] investigate the distribution problem of donated food among people exposed to food insecurity. The objective is to balance the equity and effectiveness of distributing food to the counties in the food bank's service area with the aid of mathematical models.

Table 4

Main SFSC Social Research Problems

\begin{tabular}{|c|c|c|c|c|c|}
\hline Article & Fairness & Food safety & Animal welfare & Employment/training & Others \\
\hline Krieter (2002)[58] & - & - & $\bullet$ & - & - \\
\hline Van der Gaag et al. (2004)[104] & - & $\bullet$ & - & - & - \\
\hline Manning et al. (2006)[68] & $\bullet$ & - & $\bullet$ & - & $\bullet$ \\
\hline Broek et al. (2006)[22] & - & - & $\bullet$ & - & - \\
\hline Schutz et al. (2008)[86]" & - & - & $\bullet$ & - & - \\
\hline Wang et al. (2009)[110] & - & $\bullet$ & - & - & - \\
\hline Akkerman et al. (2010)[7] & - & - & - & - & • \\
\hline Oglethorpe(2010)[75] & - & - & - & $\bullet$ & - \\
\hline Resende-Filho and Hurley (2012)[80] & - & $\bullet$ & - & - & - \\
\hline Wang et al. (2012)[111] & - & $\bullet$ & - & - & - \\
\hline Yakovleva et al. (2012)[114] & - & - & - & - & - \\
\hline Chen et al. (2013)[26] & - & - & - & $\bullet$ & - \\
\hline Piramuthu et al. (2013)[78] & - & $\bullet$ & - & - & - \\
\hline Azadnia et al. (2014)[12] & - & - & - & - & • \\
\hline Chen et al. (2014)[27] & - & $\bullet$ & - & - & - \\
\hline Ting et al. (2014)[100] & - & - & - & - & • \\
\hline Chebolu and Gaukler (2015)[25] & - & $\bullet$ & - & - & - \\
\hline Dai et al. (2015)[32] & - & $\bullet$ & - & - & - \\
\hline Davis et al. (2016)[33] & $\bullet$ & - & - & - & - \\
\hline Ghezavati et al. (2015)[46] & - & - & - & - & - \\
\hline Lee and Tongarlak (2016)[62] & $\bullet$ & - & - & - & - \\
\hline Miret et al. (2016)[71] & - & - & - & $\bullet$ & $\bullet$ \\
\hline Orgut et al. (2016)[76] & $\bullet$ & - & - & - & - \\
\hline Tang et al. (2016)[98] & - & - & - & - & $\bullet$ \\
\hline Wang et al. (2016)[109] & $\bullet$ & - & - & - & - \\
\hline
\end{tabular}

In summary, first, the studies to combine environmental and social issues as well as economic issues to achieve the best trade-off among different sustainable dimensions are very limited. Second, there is still a lack of focuses on social dimension although it attracts growing public concerns. Third, GHG emission and energy consumption are the most popular environmental topics while ecological and natural resources related issues are focused relatively little. Fourth, among the social dimension, food safety is the most investigated aspect while animal 
welfare and fairness are addressed little although they are closely associated with the typical characteristics of SFSC. In addition, food safety is closely related to temperature controled by energy use that is usually accompanied by GHG emission, but rare papers address them simultaneously.

\subsection{SCActors}

Different SC actors including farmers, processors, distributors, non-profit-organizations, and industry sectors or macro-economy (Ind./macro-ecom) involve in SFSC (Table 5). The analysis of industry sectors attracts the most attention although processors and distributors also play important roles in the focus of the studies. Almost all of the papers on industry sectors consider environmental issues except one while many papers focusing on processors address problems relevant to social issues. Non-profit organizations are relatively seldom of interest in the literature. All papers on agricultural producers involve the environmental dimension, especially ecological issues. Three of four papers on non-profit organizations mainly analyze how various non-profit organizations provide the food to needy families through sustainable supply chain. Mohan et al. (2013)[72] detail how the organization is able to improve the efficiency and effectiveness of its operations that resulted in more food reaching the food insecure by partnering with a local university. Orgut et al. (2016) [76] address equitable and effective distribution of donated food under capacity constraints. S“onmez et al. (2016)[96] proposed a model to derive general operational insights and applied the model to the food bank of the Southern Tier in New York.

Our review shows that studies on processors, distributors, as well as industry section are very popular while important actors in SFSC such as customers, farmers and non-profit organizations are rarely considered. Frist, there is no paper discussing the consumers' preference for sustainable attributes of food production and consumption, especially consumer social responsibility, which may significantly affect the optimization of SFSC. Second, all reviewed literature on farmers mainly focuses on their agricultural production decisions, however, there is no work on how to protect their fair profit in the entire food supply network. Third, the number of studies on non-profit organizations operations (only three papers) is still very small despite their emergence and rapid development in

many coutries.

Table 5

Number of Papers Published by SC Actors

\begin{tabular}{ccccccc}
\hline Article & Env & Soc & Env+Soc+Eco & Soc+Eco & Env+Eco & Total \\
\hline Agricultural Producers & 0 & 0 & 1 & 1 & 4 & 6 \\
Food Processors & 0 & 0 & 1 & 8 & 5 & 14 \\
Distributers & 0 & 0 & 0 & 2 & 9 & 11
\end{tabular}




\begin{tabular}{ccccccc} 
Non-profit organizations & 0 & 1 & 0 & 3 & 0 & 4 \\
Ind./macro-ecom & 10 & 1 & 1 & 0 & 8 & 20 \\
\hline
\end{tabular}

\subsection{Modeling Approaches and Solution Methods}

\subsubsection{Mathematical Programming Models}

A variety of modeling approaches have been used to solve research problems in SFSC. In general, we can divide related literature in three main categories: mathematical programming models, analytical models and simulation models. Mathematical programming is the preferred choice to address SFSC environmental, social and economic problems, accounting for almost a half of our considered list of papers, as in Table 6.

For models with a single objective, many papers take cost/revenue as the objective and model the environment or social issues as a constraint. The objective functions in Broek et al. 2006[22] and Schutz et al. 2008[86] min-“ imize the total cost of locating slaughterhouses and allocating animals in the different farming districts to these slaughterhouses. They consider animal welfare by limiting a maximum trip time for animals in eight hours accoring to EU regulations for aminal transportation. The objective function in Orgut et al. (2016)[76] minimizes the amount of undistributed food at a food bank suject to a user-specified constraint on the magnitude of each country's deviation from perfect equity to for the equitable and effective distribution of food donations. The objective functions in dos Santos et al. (2010)[37] and Costa et al. (2011)[31] maximize the profit subject to ecologically-based constraints. Some papers directly address a pure environmental objective. For example, the objective function in Alfandari et al. (2014)[9] minimizes the total surface area of land used to satisfy crop demands during every period in a multi-period production planning problem. Accorsi et al. (2016)[4] optimize infrastructure, agriculture, and logistics costs in the objective function with carbon emissions as a constraint. However, no paper models social issues directly in the objective function, and no paper considers two or three different sustainable dimensions as a weighted objective, unlike that in the general SSC literature (Eskandarpour et al. (2015)[42]).

Multi-objective models have been extensively used in SFSC. Twelve papers use economic and environmental biobjective with GHG emission as the environmental objective in ten of them. For example, Govindan et al. (2014)[49] deal with a two-echelon location-routing problem with time-windows for SFSC network design by proposing a multi-objective programming model that simultaneously minimizes logistics cost and environmental impacts of $\mathrm{CO}_{2}$ emissions. Soysal et al. (2014)[94] discuss a beef logistics network problem by proposing a multiobjective programming model to minimize total logistics cost and total amount of GHG from transportation 
operations. Validi et al. (2014)[103] propose a case analysis of a sustainable food supply chain distribution system in the dairy industry by minimizing GHG emissions and total distribution cost. Bortolini et al. (2016)[19] develop a three-objective programming model for fresh food sustainable distribution, however, only two sustainable dimen-

Table 6

Mathematical Programming Models

\begin{tabular}{|c|c|c|c|c|c|c|c|}
\hline Article & Dimension & Single-Objective & Multi-Objective & LP & NLP & MIP & SP \\
\hline Broek et al. (2006)[22] & SoctEco & $\bullet$ & - & - & $\bullet$ & $\bullet$ & - \\
\hline Schutz et al. (2008)[86]" & $\mathrm{Soc}+\mathrm{Eco}$ & - & - & - & $\bullet$ & $\bullet$ & - \\
\hline Wang et al. (2009)[110] & $\mathrm{Soc}+\mathrm{Eco}$ & - & - & - & $\bullet$ & - & - \\
\hline Akkerman et al. (2010)[7] & $\mathrm{Soc}+\mathrm{Eco}$ & $\bullet$ & - & $\bullet$ & - & $\bullet$ & - \\
\hline dos Santos et al. (2010)[37] & Env+Eco & $\bullet$ & - & $\bullet$ & - & $\bullet$ & - \\
\hline Costa et al. (2011)[31] & Env+Eco & $\bullet$ & - & - & - & - & $\bullet$ \\
\hline Nicholson et al. (2011)[74] & Env+Eco & $\bullet$ & - & - & $\bullet$ & - & - \\
\hline Cholette (2011)[29] & $\mathrm{Env}+\mathrm{Eco}$ & $\bullet$ & - & - & - & $\bullet$ & - \\
\hline Rong et al. (2011)[83] & Env+Eco & $\bullet$ & - & $\bullet$ & - & $\bullet$ & - \\
\hline Alfandari et al. (2014)[9] & Env & $\bullet$ & - & $\bullet$ & - & - & - \\
\hline Atallah et al. (2014)[11] & Env+Eco & $\bullet$ & - & $\bullet$ & - & - & - \\
\hline Borodin et al. (2014)[16] & Env+Eco & $\bullet$ & - & $\bullet$ & - & $\bullet$ & $\bullet$ \\
\hline Ghezavati et al. (2015)[46] & $\mathrm{Soc}+\mathrm{Eco}$ & $\bullet$ & - & $\bullet$ & - & $\bullet$ & - \\
\hline Gonela et al. (2015)[48] & Env+Eco & $\bullet$ & - & • & - & $\bullet$ & $\bullet$ \\
\hline Meneghetti-Monti et al. (2015)[69] & Env+Eco & $\bullet$ & - & - & - & - & - \\
\hline Abedi and Zhu (2016)[1] & Env+Eco & $\bullet$ & - & $\bullet$ & - & $\bullet$ & - \\
\hline Accorsi et al. (2016)[4] & Env+Eco & $\bullet$ & - & $\bullet$ & - & - & - \\
\hline Hu et al. (2016)[54] & $\mathrm{Env}+\mathrm{Eco}$ & $\bullet$ & - & $\bullet$ & - & $\bullet$ & - \\
\hline Orgut et al. (2016)[76] & $\mathrm{Soc}+\mathrm{Eco}$ & $\bullet$ & - & $\bullet$ & - & - & - \\
\hline Rocco and Morabito (2016)[81] & Env+Eco & $\bullet$ & - & $\bullet$ & - & - & - \\
\hline Oglethorpe (2010)[75] & $\mathrm{Env}+\mathrm{Soc}+\mathrm{Eco}$ & - & $\bullet$ & - & - & - & - \\
\hline Amorim et al. (2012)[10] & Env+Eco & - & $\bullet$ & $\bullet$ & - & - & - \\
\hline Govindan et al. (2014)[49] & Env+Eco & - & $\bullet$ & • & - & - & - \\
\hline Validi et al. (2014)[103] & Env+Eco & - & $\bullet$ & - & - & - & - \\
\hline Azadnia et al. (2014)[12] & $\mathrm{Env}+\mathrm{Soc}+\mathrm{Eco}$ & - & $\bullet$ & - & - & - & - \\
\hline Soysal et al. (2014)[94] & Env+Eco & - & $\bullet$ & - & - & - & - \\
\hline Soysal et al. (2015)[95] & Env+Eco & - & $\bullet$ & - & - & - & - \\
\hline Bortolini et al. (2016)[19] & Env+Eco & - & $\bullet$ & $\bullet$ & - & - & - \\
\hline Bozorgi (2016)[20] & Env+Eco & - & $\bullet$ & $\bullet$ & - & $\bullet$ & - \\
\hline Guo et al. (2016)[50] & Env+Eco & - & $\bullet$ & - & - & $\bullet$ & - \\
\hline Miret et al. (2016)[71] & $\mathrm{Env}+\mathrm{Soc}+\mathrm{Eco}$ & - & $\bullet$ & - & - & - & - \\
\hline Banasik et al. (2016a)[13] & Env+Eco & - & $\bullet$ & $\bullet$ & - & $\bullet$ & - \\
\hline Banasik et al. (2016b)[14] & Env+Eco & - & - & • & - & - & - \\
\hline
\end{tabular}


Bortolini et al. (2016)[18] Env+Eco

Colicchia et al. (2016)[30]

Env+Eco

sions of operating cost and carbon footprint are modeled in the objective function. Bozorgi (2016)[20] investigate

a multi-product inventory problem for cold items to determine the inventory levels that minimize either the cost or carbon-equivalent emissions. However, no paper considers social objective in their bi-objective models. Only three papers integrate all three sustainable dimensions in their objective function. Oglethorpe (2010)[75] use a goal programming approach to optimize economic, environmental and social objectives in the food industry. Azadnia et al. (2015)[12] develop an integrated approach with multi-objective mathematical programming for sustainable supplier selection and lot-sizing order determination problem, that simultaneously minimizes total cost and maximizes total social score, total environmental score and total economic qualitative score.

Across all single- or multi- objective models, LP and MIP are the most frequently used. However, only four papers use stochastic programming (SP) for SFSC although handling uncertainty plays an important role in FSC. Schutz et al. (2008)[86] provide a two-stage stochastic programming formulation for facility location with general"“ longrun costs and convex short-run costs based on a real-life case from the Norwegian meat industry, where the short-run costs and demand are considered as uncertain parameters. Costa et al. (2011)[31] develop a two-stage SP with uncertain demands for sustainable vegetable crop supply problem with perishable stocks. Gonela et al. (2015)[48] develop a stochastic mixed integer linear programming model for a bioethanol supply chain under different sustainability standards considering uncertainties in demand, price and biomass yield.

\subsubsection{Analytical Models and Simulation Models}

Among the analytical approaches, as in Table 7, life cycle assessment (LCA) is exclusively used to analyze environment-related issues. Nine of the papers consider the environmental dimension while three of the papers address both environmental and economic dimensions. Most LCA-based papers focus on a specific context or case application (Seuring (2013)[87]), such as fresh tomato distribution (Roy et al. (2008)[85]), a case study on food catering supply chain (Accorsi et al. (2014)[3]), packaged tomato puree (Manfredi and Vignali (2014)[67]), and production and distribution of endive (Tasca et al. (2016)[99]). In the analytical models category, four papers use game theory to address social issues. Simulation models chosen by seven papers are less often employed than mathematical programming and analytical models. Other models include forecast models (Davis et al. (2016)[33]), and analytic hierarchy process (AHP) (Yakovleva et al. (2012)[114]). 


\subsubsection{Solution Methods}

This subsection discusses the solution methods used to solve SFSC models, as in Table 8. Since most of the analytical models and simulation models for SFSC are solved with similar solution methods (for example, KarushKuhn-Tucker (KKT) conditions), we mainly focus on methods solving mathematical programming models. We analyze the methods for singe-objective models followed by those for multi-objective models.

Heuristics and column-generation are the most used methods because of the NP-hard property of the problems for single objective models. Eight papers directly use commercial solvers such as CPLEX, Gurobi, Lingo etc. Other

Table 7

Analytical and Simulation Models

\begin{tabular}{|c|c|c|c|c|c|}
\hline Article & Dimension & LCA & Game theory & AM-other & Simulation \\
\hline Sonesson and Berlin (2003) [92] & Env & $\bullet$ & - & - & - \\
\hline Roy et al. (2008)[85] & Env & $\bullet$ & - & - & - \\
\hline Vanek and Sun (2008)[107] & Env & $\bullet$ & - & - & - \\
\hline Virtanen et al. (2011)[108] & Env & $\bullet$ & - & - & - \\
\hline Meneses et al. (2012)[70] & Env & $\bullet$ & - & - & - \\
\hline Abeliotis et al. (2013)[2] & Env & $\bullet$ & - & - & - \\
\hline Webb et al. (2013)[112] & Env & $\bullet$ & - & - & - \\
\hline Accorsi et al. (2014)[3] & Env+Eco & $\bullet$ & - & - & - \\
\hline Del Borghi et al. (2014)[34] & $\mathrm{Env}+\mathrm{Eco}$ & $\bullet$ & - & - & - \\
\hline Manfredi and Vignali (2014)[67] & Env+Eco & $\bullet$ & - & - & - \\
\hline Kulak et al. (2016)[59] & Env & $\bullet$ & - & - & - \\
\hline Tasca et al. (2016)[99] & Env & $\bullet$ & - & - & - \\
\hline Resende-Filho and Hurley (2012)[80] & $\mathrm{Soc}+\mathrm{Eco}$ & - & • & - & - \\
\hline Chen et al. (2013)[26] & $\mathrm{Soc}+\mathrm{Eco}$ & - & $\bullet$ & - & - \\
\hline Chen et al. (2014)[27] & $\mathrm{Soc}+\mathrm{Eco}$ & - & • & - & - \\
\hline Tang et al. (2016)[98] & $\mathrm{Env}+\mathrm{Soc}+\mathrm{Eco}$ & - & $\bullet$ & - & - \\
\hline Yakovleva et al. (2012)[114] & $\mathrm{Env}+\mathrm{Soc}+\mathrm{Eco}$ & - & - & $\bullet$ & - \\
\hline Zanoni and Zavanella (2012)[115] & Env+Eco & - & - & • & - \\
\hline Piramuthu et al. (2013)[78] & $\mathrm{Soc}+\mathrm{Eco}$ & - & - & $\bullet$ & - \\
\hline Dai et al. (2015)[32] & $\mathrm{Soc}+\mathrm{Eco}$ & - & - & • & - \\
\hline Li and Wang (2015)[63] & $\mathrm{Env}+\mathrm{Eco}$ & - & - & • & - \\
\hline Ai et al. (2016)[6] & Env+Eco & - & - & $\bullet$ & - \\
\hline Lee and Tongarlak (2016)[62] & $\mathrm{Env}+\mathrm{Soc}+\mathrm{Eco}$ & - & - & • & - \\
\hline Sgarbossa-Russo (2016)[88] & Env+Eco & - & - & • & - \\
\hline Wang et al. (2016)[109] & Env+Soc & - & - & $\bullet$ & - \\
\hline Krieter (2002)[58] & $\mathrm{Env}+\mathrm{Soc}+\mathrm{Eco}$ & - & - & - & - \\
\hline Van der Gaag et al. (2004)[104] & Soc & - & - & - & • \\
\hline
\end{tabular}


Van der Vorst et al. (2009)[106]

Mohan et al. (2013)[72]

Chebolu and Gaukler (2015)[25]

Chang et al. (2016)[24]

Ivanov et al. (2016)[55]
Env+Eco

Soc+Eco

Soc

Env+Eco

Env+Eco

methods include Benders decomposition, sampling average approximation, constraint programming, branchandprice-and-cut combined with column-generation, and approximative scenario reduction algorithms.

For multi-objective SFSC models, $\varepsilon$-constraint is the most widely employed solution method. More than a quarter of the papers solve multi-objective models with such a method. Goal programming, the weighted sum of the objective functions are also frequently used. Similar to single-objective models, several papers apply commercial solvers such as CPLEX to directly solve the subproblem of multi-objective models.

In summary, first, analytical and simulation models, especially game theory based models, are more popular in Table 8

Solution Methods for Single and Multiple Objective Problems

\begin{tabular}{|c|c|c|c|c|}
\hline Type & Article & Dimension & Solution method & Solver tool \\
\hline \multirow[t]{17}{*}{ Single-objective } & Broek et al. (2006)[22] & SoctEco & Heuristic based on Lagrangean relaxation & - \\
\hline & Schutz et al. (2008)[86]" & SoctEco & Heuristic based on Lagrangean relaxation & - \\
\hline & dos Santos et al. (2010)[37] & $\mathrm{Env}+\mathrm{Eco}$ & Column-generation & With the aid of CPLEX \\
\hline & Akkerman et al. (2010)[7] & SoctEco & - & CPLEX \\
\hline & Cholette (2011)[29] & Env+Eco & Only Gurobi & Gurobi \\
\hline & Costa et al. (2011)[31] & Env+Eco & Column-generation & With the aid of CPLEX \\
\hline & Nicholson et al. (2011)[74] & Env+Eco & Only CPLEX & CPLEX \\
\hline & Rong et al. (2011)[83] & Env+Eco & Only CPLEX & CPLEX \\
\hline & Hasani et al. (2012)[53] & Env+Eco & - & Lingo \\
\hline & Atallah et al. (2014)[11] & Env+Eco & - & - \\
\hline & Borodin et al. (2014)[16] & $\mathrm{Env}+\mathrm{Eco}$ & Approximative scenario reduction algorithms & CPLEX \\
\hline & Alfandari et al. (2015)[9] & Env & Branch-and-Price-and-Cut, Column-generation & Compared to CPLEX \\
\hline & Ghezavati et al. (2015)[46] & Soc+Eco & Benders decomposition & Compared to CPLEX \\
\hline & Gonela et al. (2015)[48] & Env+Eco & Sampling average approximation & - \\
\hline & Meneghetti-Monti et al. (2015)[69] & Env+Eco & Constraint programming approach & - \\
\hline & Abedi and Zhu (2016)[1] & Env+Eco & - & GAMS \\
\hline & Accorsi et al. (2016)[4] & Env+Eco & Only Gurobi & Gurobi \\
\hline
\end{tabular}




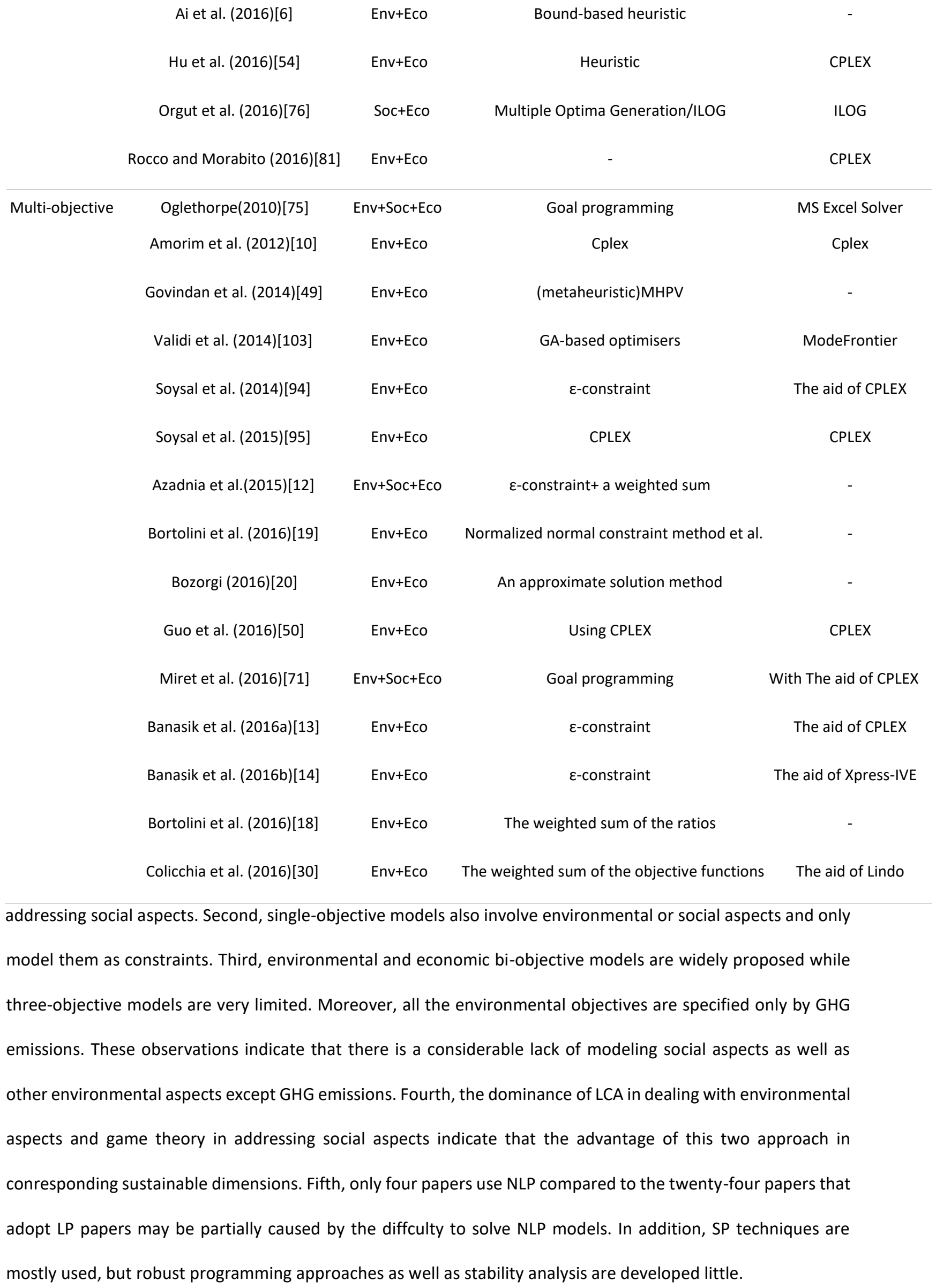

As for solution methods, we have the following findings. First, although heuristics and column-generation dominate for single-objective models, and $\varepsilon$-constraint and the weighted sum methods dominate for multi- 
objective models, commercial solvers as CPLEX, Gurobi, Lindo, and Express play very important roles for both types of models. Second, metaheuristics are employed relatively rarely although most SFSC problems are NPhard. A possible reason is that many of the papers address real-world cases in which the problem sizes are small. Thus, there is a lack of efficient solution methods for more complex SFSC problems. Third, as the main solution methods for multi-objective models, $\varepsilon$-constraint, the weighted sum methods and goal programming also mainly rely on the aid of commercial solver to solve the subproblem of multi-objective models, which indicates that the possible barrier in such methods to solve more large-sized problems. Fourth, although many solution methods have been applied in our reviewed papers, there are still number of solution methods that have been shown to be effective in general SC such as convex optimization, dynamic programming, and metaheuristic that are not generally used to solve SFSC problems.

\subsection{Other}

In this subsection, we analyze papers on other important dimensions including the countries that the papers have specifically considered, types of food products as well as uncertainty.

\subsubsection{Country context}

For the country context, the assessment is based on the countries that the papers have addressed. Table 8 shows the geographic distribution of the existing model-based SFSC research. A majority of published papers (70\%) are based on individual country-specific issues. There are 46 papers that cover developed countries, including Italy, USA, UK, Germany, Netherlands, France, Australia, Spain, Greece, Sweden, Ireland, Norway, Finland, and Japan. There are 9 papers that cover developing countries, including Brazil, China, Turkey, India, and Iran. The geographical distribution in this domain is clearly imbalanced. One possible reason is that the major FSC research in developing countries mianly concerns economic objectives such as how to increase food gain to feed the population igoring the environmental and social dimensions of FSC (Shukla and Jharkharia (2013)[90]).

Consequently, we have the following observations. On one side, developed countries have been popularly examined while developing countries have not been well-explored, which may lead to the barrier in the application of the findings and models generated from developed coutries to developing countries due to due to the differences in income, infrastructure, and consumer preference between these two types of countries. On the other side, almost all the models that we reviewed focus on domestic SFSC network, signifying that the decisions considered are within a single country, e.g. USA, Germany, etc. However, the global features play 
increasingly important role in SFSC due to the rapid development of international trade in the world which may necessitate new sustainable issues to be modeled. For instance, imported fruits and vegetables in USA and China have increased $9.0 \%$ and $20.9 \%$ respectively from 2009 to 2015 according to calculation with UN comtrade data. Water resources, N, and P emission embedded in the food flow in global supply chains are ignored. In addition, fair trade is also closely associated with global food supply chain. Although there exist some reviews that investigate global supply chain on industrial products, none of them consider food products or discuss sustainable issues in global food supply chains.

Table 9

Number of Papers Published by Countries

\begin{tabular}{|c|c|c|c|c|c|c|}
\hline Article & Env & Soc & $\mathrm{Env}+\mathrm{Soc}+\mathrm{Eco}$ & $\mathrm{Soc}+\mathrm{Eco}$ & Env + Eco & Total \\
\hline Italy & 1 & 0 & 0 & 1 & 8 & 10 \\
\hline USA & 1 & 0 & 0 & 4 & 5 & 10 \\
\hline UK & 2 & 2 & 2 & 1 & 2 & 9 \\
\hline Germany & 0 & 0 & 1 & 1 & 0 & 2 \\
\hline Netherlands & 0 & 1 & 0 & 1 & 2 & 4 \\
\hline Brazil & 0 & 0 & 0 & 0 & 3 & 3 \\
\hline France & 1 & 0 & 1 & 0 & 0 & 2 \\
\hline Australia & 0 & 0 & 0 & 0 & 2 & 2 \\
\hline Spain & 1 & 0 & 0 & 0 & 0 & 1 \\
\hline Greece & 1 & 0 & 0 & 0 & 0 & 1 \\
\hline Sweden & 1 & 0 & 0 & 0 & 0 & 1 \\
\hline Ireland & 0 & 0 & 0 & 0 & 1 & 1 \\
\hline Norway & 0 & 0 & 0 & 1 & 0 & 1 \\
\hline Finland & 1 & 0 & 0 & 0 & 0 & 1 \\
\hline Turkey & 0 & 0 & 0 & 0 & 1 & 1 \\
\hline China & 0 & 0 & 0 & 2 & 0 & 2 \\
\hline Japan & 1 & 0 & 0 & 0 & 0 & 1 \\
\hline India & 0 & 0 & 0 & 1 & 1 & 2 \\
\hline Iran & 0 & 0 & 0 & 1 & 0 & 1 \\
\hline Multi-national & 0 & 1 & 0 & 0 & 2 & 3 \\
\hline
\end{tabular}

4.4.2 Types of food products

Type of food product is categorized dependent on animal-based food products such as meat, milk, eggs, sausages, etc., and plant-based food products such as vegetables, fruits, grains, meals, sauces, and wine. There are 15 papers addressing animal-based food products and 26 papers related to plant-based food products. A majority of the papers on animal-based food products deal with social issues while most papers on plant-based food products focus on environment-related issues. The main difference is that the production and supply of animal- 
based food products usually involve more social issues such as animal welfare and food safety risks, while those of plantbased food products incur more potential environmental problems such as ecological issues, synthetic fertilizers, as well as emission. These two streams of food supply chain face problems that have their unique characteristics, and consequently researchers need to consider these details when choosing applicable models. Research problems that involve both animal- and plant- based products generate further complications and create challenges in finding solutions.

\subsubsection{Uncertainty}

A majority of the reviewed papers focus on deterministic issues of SFSC although uncertainty is a key feature of SFSC. Only four papers consider uncertainty issues, however, none of them deal with social or environmental sustainability related uncertainty issues. For example, Schutz et al. (2008)[86] study slaughterhouse location prob-" lem considering the legal restrictions on more than 8 hours of transport for animal welfare. Although uncertainty is considered in their work, the uncertain components include only demand and cost disregarding any sustainable issues, e.g., animal welfare is modeled as a deterministic constraint. The sustainable uncertainty of SFSC involves two sides of demand and supply. On the supply side, the sustainable uncertainty comes from the risk of adverse weather condition, the disease of livestock or crops and pests, etc. (Borodin et al. (2016)[17]). On the demand side, sustainable uncertainty comes from the variety of consumers' preference for sustainable attribute and willingness to pay for such attribute. For instance, there exist huge differences in consumer's preference for organic attribute / fair trade which may affect food production and even the entire FSC. In addition, food safety risks along the entire chain bring great uncertainty challenges for managerial decision making. Therefore, knowledge on how to model the food safety risk and recover the supply chain is of paramount importance.

$5 \quad$ Challenges \& Future Research Opportunities

In this section we present potential future research opportunities based on the above analysis. A vast number of studies address modeling sustainable issues for general supply chain, however there still exists a great need to deal with SFSC (Brandenburg et al. 2014[21], and Seuring 2013[87]). The specific sustainable dimensions of FSC are very different from those of a general supply chain, and many new issues related to the characteristics of FSC are yet to be addressed. Emerging trends and their sources with respect to major perspectives of the sustainable food supply chain are listed. Overall, from the perspective of sustainability, it is urgent to develop further models 
that are able to integrate economic, environmental, and social issues, as in discussion in consumer preferences, global sustainable food supply chain, sustainable regional food supply chain considering food hubs, and temperature controled sustainable distribution. Non-profit supply chain to alleviate food insecurity, farmers welfare, animal welfare, and highly integrated traceability-driven food supply chain belong the social aspect. Novel modeling approaches \& solution methods, the application in developing countries and of digital technologies \& data analytics, as well as sustainable risk management in SFSC are discussed last.

\subsection{Consumer Preferences}

Consumer preferences for sustainable food consumption is an important topic in food supply chain. While there are some empirical studies to this regard, we are not aware of any published FSC modeling studies that consider consumer preference for sustainable food consumption. With the increase in awareness on sustainability, consumers consider more sustainable issues (e.g., low energy consumption, low emission, fair trade, etc. ) while making food choices, and are willing to pay different prices for different sustainable levels of food. Almost all existing modeling studies on food supply chain consider consumer demand as a monolithic concept with no regard for differences in consumer preferences toward sustainable food consumption. However, consumer's preferences toward sustainable food are closely related to food demand as witnessed through their willingness to pay and will affect other decisions throughout the entire FSC. Examples of these include farmers' production methods (organic or traditional), distributors' transportation decisions (low vs. high energy consumption/emission), and manufacturers' global supply chain network decision (e.g., purchasing coffee from developing countries considering fair trade). Therefore, incorporating consumers' sustainable preferences as well as their willingness to pay into the modeling of FSC is a very promising research direction involving three sustainable dimensions.

\subsection{Global Sustainable Food Supply Chain}

The unprecedented and widespread expansion of food supply chains farther into far-flung and international locations as a result of globalization has resulted in increased complexity of sustainable problems. From an environmental perspective, water resource use and emissions (e.g., N, P, C) generated by agricultural production (e.g., water, N, P, C) and global logistics (e.g., emission from shipping liners) are closely tied to food distribution along the global supply chain. From a social perspective, fair trade initiatives that link small producers (e.g., coffee farmers) in developing countries with socially-conscious consumers in the developed countries has grown rapidly during the past decade. For example, the fair trade sector involved over 1.2 million farmers and workers in more 
than sixty countries with about 60 percent of sales related to food products such as coffee, cocoa, wine, sugar, fresh fruit, and chocolate (Ladhari and Tchetgna 2015[61], Raynolds 2000 [113]). Therefore, designing and modeling global sustainable food supply chain by integrating features of food (e.g., perishability, the consumption of natural resources, the emission pollution) and the above sustainable (social) issues into global supply chain models is an important research topic.

\subsection{Sustainable Regional (Local) Food Supply Chain Considering Food Hubs}

With a key role in regional food supply chains, food hubs are increasingly seen as vectors for economic growth and environmental and social change by diverse stakeholders due to consumers' growing demand for local/regional foods (Hardy et al 2016) [52]. Food hubs embedded in regional food supply systems include several sustainable characteristics such as the provision of increased retail market access to outputs from small- and medium- sized farms, vested interest to improve human health since most farmers and customers are regional and are located within a 400 mile radius, close association with food donation to food banks, and the development of initiatives to ensure fair returns to farmers. (Hardy et al. 2016 [52], Fischer et al. 2013[43]). Regional food supply systems with food hubs have received well-deserved attention from practitioners as well as policy makers. One such is USDA's regional "food hub" services to develop regional and local food system together with farmers, wholesalers, and retailers (Etemadnia et al. 2015[41]). However, such interest from practitioners and policy makers has not yet successfully transitioned into academia where there are very few studies that focus on regional food supply chain, especially from the perspectives of sustainability and modeling. Interesting unanswered research questions can potentially be found in modeling sustainable regional food supply chain with food hubs.

\subsection{Temperature Controled Sustainable Distribution}

There are some papers discussing the relationship between temperature and food safety/quality, however, there is a lack of studies on integrating further energy consumption, emission, and safety/quality into general food supply chain optimization models. For example, how to balance the goal of energy consumption which is a fundation to guarantee food safet/quality by controlling the temperature, emission, as well as cost during distribution including transportation and inventory management, etc. 


\subsection{Non-Profit Supply Chain to Alleviate Food Insecurity}

There still exist a great number of food-insecure individuals who are at risk for not being able to acquire enough food, despite increases in global food production. For instance, over $14 \%$ of household were estimated by the USDA (United States Department of Agriculture) in 2013 to be food-insecure in the USA, which is one of the most developed countries [96]. The cause for such dismal figures is not production shortages but the challenge to get available food to reach the needy in a timely manner due to the uneven distribution of food resources that creates wastage in some areas and food insecurity in other areas. Non-profit organizations such as food banks act as food intermediaries by processing and distributing donated food from organizations or individuals to foodinsecure individuals. Food banks play an increasingly important role in the food supply chain for reducing food loss and alleviating the effects of food insecurity (Mohan et al. 2013[72]). The dynamic of such SCs are very different from that in a general supply chain, since their objective is not profit but equity. However, there are very few published research work that focus on modeling non-profit supply chains to alleviate food insecurity. Therefore, further research that considers the role and mechanism of the non-profit food supply network provides an important starting point for related unanswered research questions.

\subsection{Farmers Welfare}

Although farmers play a significant role in SFSC, they are often neglected in published research studies that optimize production and supply. Farmers, especially small farmers usually have weak market power compared to their competitors. Considering farmers' welfare while modeling food supply chain so that small farmers can receive fair treatment from the market and the government is an important social question. Sodhi and Tang (2014)[91] have offered some insights into new avenues for addressing such issues.

\subsection{Animal welfare}

Animal-based food products account for a large proportion of food, and the supply chain of such products usually involves animal welfare related issues such as breeding, transporting, slaughtering livestocks, among others. Extant published research literature only models animal welfare as a constraint rather than as an objective. Integrating ethics related issues into SFSC modeling has significant potential as a valuable exercise. 


\subsection{Highly Integrated Traceability-Driven Food Supply Chain}

Traceability, which includes product traceability, process traceability, genetic traceability, inputs traceability, disease and pest traceability and measurement traceability, plays an important role in controlling various environmental SFSC problems (Piramuthu and Zhou (2016)[79]). Although several published research papers have discussed traceability applications in food supply chain, missing elements still abound in food supply chain traceability models. For example, with the aid of RFID-generated visibility, a food company is able to obtain realtime stock flow of food products as well as contamination information throughout its (cold) production and distribution network. Therefore, how to (re)design and optimize the food supply network based on such realtime information is a valuable problem to be addressed.

\subsection{Sustainable Farming}

Seasonal planning optimization is an important environmental research problem. Land becomes barren after several farm seasons with the same crop (livestock). Current practices and state-of-the-art research are somehow not optimized if not completely very "unsustainable" such as the blanket overuse of fertilizers, pest control chemicals, and clean water. Long-term planning optimization therefore should become a very important part of FSC sustainability research. Given that very few studies on this topic are based on OR methods, there are still numerous open research problems in this domain that beg to be modeled.

\subsection{Novel Modeling Approaches \& Solution Methods}

Many sustainable issues of SFSC especially social topics are indeed difficult to be modeled directly while empirical research methods provide useful tools for this purpose. Therefore, in line with general SSC (Brandenburg et al. (2014)[21]), model-oriented method with empirical study is highly recommended to address problems in SFSC. A recent paper by Sheu (2016)[89] on general green supply chain management provides such an example.

Modeling approaches are generally adopted independently. However, most real-world SFSC problems are very complex, and a hybrid of the modeling approaches may reveal more significant managerial insights in SFSC. Linking linear programming with game theory is a potentially better approach to model competitive SFSC network design problems. Similarly, a hybrid of linear programming and LCA may reveal valuable information from the SCM level to that of the industry sector. In addition, modeling further complicated real-world SFSC problems with NLP provides challenging opportunities. 
For stochastic environments, robust programming approaches as well as stability analysis are also interesting ways and should be developed. Although many solution methods have been applied in our reviewed papers, there are still many solution methods that have been shown to be effective in general SC such as convex optimization, dynamic programming, and metaheuristic that are not generally used to solve SFSC problems. This indicates the possibility to address more complicated SFSC problems with such effective solution methods. In addition, due to the rapid advances in commercial solvers, further application of solvers in future development of efficient solution methods for solving complicated SFSC models is also promising.

\subsection{Application in Developing Countries}

Food supply chain is very context based. More than $70 \%$ of the papers we considered for this study concern specific issues in an individual country, with a significant majority that focus on developed countries. However, the application of a model-oriented method in SFSC in developing countries is urgently needed since the contexts of these two types of countries vary widely not only in the level of economic development but also in the food supply system infrastructure as well as the expectations of the actors such as farmers and consumers. Taking China as an example, sustainability-consciousness consumers in the eastern urban areas and the large number of small farmers in western rural areas coexist, which allows for the possibility of modeling FSC considering fair trade between eastern developed areas and western developing areas. Therefore, modeling important issues that were already investigated in developed countries such as fair trade, non-profit supply chain, etc. could result in significant contribution to alleviate poverty and food insecurity in developing countries.

\subsection{Application of Digital Technologies \& Data Analytics}

Novel digital technologies are creating major opportunities for the food industry and have greatly reshaped the food supply chain. Digital technologies are connecting food producers and consumers in many new ways. Food production is becoming localized around cities, driven by demand for local food. Digital technologies such as loT (Internet of Things) can enable localized markets to thrive by sending real-time signals from consumers to growers and back along the value chain. New digital approaches in the food industry have greatly changed the business and operational processes, necessitating revisions of existing analytical models in this domain to accommodate the changes. Another major force in the digital food supply chain transformation is data analytics. For example, getting close to consumer preferences is vital for businesses in rapidly evolving markets. Nowadays, a company can leverage digital technology and data to optimize where and what they sell. Transaction data acquired in realtime empowers the food retail business to sell what consumers want, when and where they want 
it, at competitive prices. They can control their inventory to cut down waste, which also reduces costs. Data analytics has been found to be invaluable in preventing or at least reducing food wastage throughout the food supply chain. Recent advances in data analytics research methods, along with the emerging research problems in this field are challenging and create many future research opportunities.

\subsection{Sustainable Risk Management in SFSC}

Risk management is critical due to uncertainty in SFSC. However, to our knowledge, there is no published work that considers risk management in relation to sustainable uncertainty in FSC. How to model the sustainable risks in SFSC both from the supply side (e.g., livestock diseases, pests) and the demand side (e.g., evolution of changes in consumer preferences) as well as the food safety risk throughout the whole chain is of great significance.

\section{Conclusions}

We presented a comprehensive review of published model-oriented research papers in the SFSC domain. Although the number of publications is not as large as the empirical papers on this topic, it has grown rapidly especially during the past several years mostly due to the increasing consumers' concerns on food sustainability. The applied OR techniques, which are used to specifically address SFSC problems, are mostly model-oriented and vary from case to case. Despite the significance of a structured outline of SFSC research techniques, existing reviews of food supply chain (FSC) literature are rather generic and disregards explicit consideration of sustainability from a model-oriented perspective. We reviewed 83 scientific journal publications, each of which is based on relevant mathematical modeling techniques. We first identified the three relevant dimensions that include the economic, environmental and social issues in SFSC. We then reviewed the models and methods that have been applied to solve SFSC problems. Based on our observations, it is evident that previous researchers have made important contributions to the field of model-oriented SFSC. There are, however, many significant challenges and valuable research questions that are worthy of consideration. Through our review of existing published SFSC literature, we have identified specific areas with high potential for further exploration.

\section{Acknowledgements}

This work was partially supported by the French Ministries of Foreign and European Affairs and the Higher Education and Research, as well as the Chinese Ministry of Education through the Cai Yuanpei Program under 


\section{References}

[1] Abedi, A., \& Zhu, W. (2016). An optimisation model for purchase, production and distribution in fish supply chaina case study. International Journal of Production Research, 1-14

[2] Abeliotis, K., Detsis, V., \& Pappia, C. (2013). Life cycle assessment of bean production in the Prespa National Park, Greece. Journal of Cleaner Production, 41, 89-96.

[3] Accorsi, R., Cascini, A., Cholette, S., Manzini, R., \& Mora, C. (2014). Economic and environmental assessment of reusable plastic containers: A food catering supply chain case study. International Journal of Production Economics, 152, 88-101.

[4] Accorsi, R., Cholette, S., Manzini, R., Pini, C., \& Penazzi, S. (2016). The land-network problem: ecosystem carbon balance in planning sustainable agro-food supply chains. Journal of Cleaner Production, 112, 158-171.

[5] Ahumada, O., \& Villalobos, J. R. (2009). Application of planning models in the agri-food supply chain: A review. European Journal of Operational Research, 196(1), 1-20.

[6] Ai, X. Y., Zhang, J. L., \& Wang, L. (2017). Optimal joint replenishment policy for multiple non-instantaneous deteriorating items. International Journal of Production Research, 1-18.

[7] Akkerman, R., Van Der Meer, D., \& Van Donk, D. P. (2010). Make to stock and mix to order: Choosing intermediate products in the food-processing industry. International Journal of Production Research, 48(12), 3475-3492.

[8] Akkerman, R., Farahani, P., \& Grunow, M. (2010). Quality, safety and sustainability in food distribution: a review of quantitative operations management approaches and challenges. OR Spectrum, 32(4), 863-904.

[9] Alfandari, L., Plateau, A., \& Schepler, X. (2015). A branch-and-price-and-cut approach for sustainable crop rotation planning. European Journal of Operational Research, 241(3), 872-879.

[10] Amorim, P., Gnther, H. O., \& Almada-Lobo, B. (2012). Multi-objective integrated production and distribution planning of perishable products. International Journal of Production Economics, 138(1), 89-101.

[11] Atallah, S. S., Gmez, M. I., \& Bjrkman, T. (2014). Localization effects for a fresh vegetable product supply chain: Broccoli in the eastern United States. Food Policy, 49, 151-159.

[12] Azadnia, A. H., Saman, M. Z. M., \& Wong, K. Y. (2015). Sustainable supplier selection and order lot-sizing: an integrated multi-objective decision-making process. International Journal of Production Research, 53(2), 383-408.

[13] Banasik, A., Kanellopoulos, A., Claassen, G. D. H., Bloemhof-Ruwaard, J. M., \& van der Vorst, J. G. (2017). Closing loops in agricultural supply chains using multi-objective optimization: A case study of an industrial mushroom supply chain. International Journal of Production Economics, 183, 409-420.

[14] Banasik, A., Kanellopoulos, A., Claassen, G., Bloemhof-Ruwaard, J. M., \& Vorst, J. G. (2016). Assessing alternative production options for eco-efficient food supply chains using multi-objective optimization. Annals of Operations Research, 1-22.

[15] Beske, P., Land, A., \& Seuring, S. (2014). Sustainable supply chain management practices and dynamic capabilities in the food industry: A critical analysis of the literature. International Journal of Production Economics, 152, 131-143.

[16] Borodin, V., Bourtembourg, J., Hnaien, F., \& Labadie, N. (2014). A quality risk management problem: case of annual crop harvest scheduling. International Journal of Production Research, 52(9), 2682-2695.

[17] Borodin, V., Bourtembourg, J., Hnaien, F., \& Labadie, N. (2016). Handling uncertainty in agricultural supply chain management: A state of the art. European Journal of Operational Research, 254(2), 348-359. 
[18] Bortolini, M., Faccio, M., Gamberi, M., \& Pilati, F. (2016). Multi-objective design of multi-modal fresh food distribution networks. International Journal of Logistics Systems and Management, 24(2), 155-177.

[19] Bortolini, M., Faccio, M., Ferrari, E., Gamberi, M., \& Pilati, F. (2016). Fresh food sustainable distribution: cost, delivery time and carbon footprint three-objective optimization. Journal of Food Engineering, 174, 56-67.

[20] Bozorgi, A. (2016). Multi-product inventory model for cold items with cost and emission consideration. International Journal of Production

Economics, 176, 123-142.

[21] Brandenburg, M., Govindan, K., Sarkis, J., \& Seuring, S. (2014). Quantitative models for sustainable supply chain management: Developments and directions. European Journal of Operational Research, 233(2), 299-312.

[22] VD Broek, J., Schutz, P., Stougie, L., \& Tomasgard, A. (2006). Location of slaughterhouses under economies of scale. European journal of operational research, $175(2), 740-750$.

[23] Canning, P. (2011). Energy use in the US food system. Diane Publishing.

[24] Chang, X., Li, J., Rodriguez, D., \& Su, Q. (2016). Agent-based simulation of pricing strategy for agri-products considering customer preference. International Journal of Production Research, 54(13), 3777-3795.

[25] Chebolu-Subramanian, V., \& Gaukler, G. M. (2015). Product contamination in a multi-stage food supply chain. European Journal of Operational Research, 244(1), 164-175.

[26] Chen, Y.-J., J. George, S., \& Zuo-Jun Max, S. (2013). Training, production, and channel separation in ITC's E-Choupal network. Production and Operations Management, 22(2), 348-364.

[27] Chen, C., Zhang, J., \& Delaurentis, T. (2014). Quality control in food supply chain management: An analytical model and case study of the adulterated milk incident in China. International Journal of Production Economics, 152, 188-199.

[28] Chen, W. T., \& Hsu, C. I. (2015). Greenhouse gas emission estimation for temperature-controlled food distribution systems. Journal of Cleaner Production, 104, 139-147.

[29] Cholette, S. (2011). Addressing the greenhouse gas emissions associated with food distribution: a case study of Californian farmers markets. Economia agro-alimentare. 2011, 3, 145-169.

[30] Colicchia, C., Creazza, A., Dallari, F., \& Melacini, M. (2016). Eco-efficient supply chain networks: development of a design framework and application to a real case study. Production planning \& control, 27(3), 157-168.

[31] Costa, A. M., dos Santos, L. M. R., Alem, D. J., \& Santos, R. H. (2014). Sustainable vegetable crop supply problem with perishable stocks. Annals of Operations Research, 1-19.

[32] Dai, H., Tseng, M. M., \& Zipkin, P. H. (2015). Design of traceability systems for product recall. International Journal of Production Research, 53(2), 511-531.

[33] Davis, L. B., Jiang, S. X., Morgan, S. D., Nuamah, I. A., \& Terry, J. R. (2016). Analysis and prediction of food donation behavior for a domestic hunger relief organization. International Journal of Production Economics, 182, 26-37.

[34] Del Borghi, A., Gallo, M., Strazza, C., \& Del Borghi, M. (2014). An evaluation of environmental sustainability in the food in dustry through Life Cycle Assessment: the case study of tomato products supply chain. Journal of Cleaner Production, 78, 121-130.

[35] Diabat, A., Govindan, K., \& Panicker, V. V. (2012). Supply chain risk management and its mitigation in a food industry. International Journal of Production Research, 50(11), 3039-3050. 
[36] Dobbs, R., Oppenheim, J., Thompson, F., Brinkman, M., \& Zornes, M. (2011). Resource Revolution: Meeting the world's energy, materials, food, and water needs.

[37] dos Santos, L. M. R., Costa, A. M., Arenales, M. N., \& Santos, R. H. S. (2010). Sustainable vegetable crop supply problem. European Journal of Operational Research, 204(3), 639-647.

[38] Dupuy, C., Botta-Genoulaz, V., \& Guinet, A. (2005). Batch dispersion model to optimise traceability in food industry. Journal of Food Engineering, 70(3), 333-339.

[39] Guine, J., Heijungs, R., De Koning, A., Van, L., Geerken, T., Van Holderbeke, M., ... \& Delgado, L. (2006). Environmental Impact of Products (EIPRO) Analysis of the life cycle environmental impacts related to the final consumption of the EU25.

[40] Eklington, J. (1998). Cannibals with forks: The Triple Bottom Line of the 21st century.

[41] Etemadnia, H., Goetz, S. J., Canning, P., \& Tavallali, M. S. (2015). Optimal wholesale facilities location within the fruit and vegetables supply chain with bimodal transportation options: An LP-MIP heuristic approach. European Journal of Operational Research, 244(2), $648-661$.

[42] Eskandarpour, M., Dejax, P., Miemczyk, J., \& Pton, O. (2015). Sustainable supply chain network design: An optimization-oriented review. Omega, 2015, 54, 1-32.

[43] Fischer, M., Hamm, M., Pirog, R., Fisk, J., Farbman, J., \& Kiraly, S. (2013). Findings of the 2013 national food hub survey. Michigan State University Center for Regional Food Systems \& The Wallace Center at Winrock International.

[44] CIAA (Confederation of the Food and Drink Industries in the EU). (2010). Supporting the competitiveness of the European food and drink industry. CIAA Competitiveness Report, Brussels.

[45] France food and drink report, (2012/2013 edition). (2012). Retrieved from https://store.bmiresearch.com/france-food-drinkreport.html.

[46] Ghezavati, V. R., Hooshyar, S., \& Tavakkoli-Moghaddam, R. (2015). A Benders decomposition algorithm for optimizing distribution of perishable products considering postharvest biological behavior in agri-food supply chain: a case study of tomato. Central European Journal of Operations Research, 1-26.

[47] Glen, J. J. (1987). Mathematical models in farm planning: A survey. Operations Research, 35(5), 641-666.

[48] Gonela, V., Zhang, J., \& Osmani, A. (2015). Stochastic optimization of sustainable industrial symbiosis based hybrid generation bioethanol supply chains. Computers \& Industrial Engineering, 87, 40-65.

[49] Govindan, K., Jafarian, A., Khodaverdi, R., \& Devika, K. (2014). Two-echelon multiple-vehicle locationrouting problem with time windows for optimization of sustainable supply chain network of perishable food. International Journal of Production Economics, 152, $9-28$.

[50] Guo, M., Richter, G. M., Holland, R. A., Eigenbrod, F., Taylor, G., \& Shah, N. (2016). Implementing land-use and ecosystem service effects into an integrated bioenergy value chain optimisation framework. Computers \& Chemical Engineering, 91, 392-406.

[51] Hall, J., Matos, S., \& Silvestre, B. (2012). Understanding why firms should invest in sustainable supply chains: a complexity approach. International journal of production research, 50(5), 1332-1348.

[52] Hardy, J., Hamm, M., Pirog, R., Fisk, J., Farbman, J., \& Fischer, M. (2016). Findings of the 2015 National Food Hub Survey. Michigan State University Center for Regional Food Systems: East Lansing, MI, USA. 
[53] Hasani, A., Zegordi, S. H., \& Nikbakhsh, E. (2012). Robust closed-loop supply chain network design for perishable goods in agile manufacturing under uncertainty. International Journal of Production Research, 50(16), 4649-4669.

[54] Hu, H., Zhang, Y., \& Zhen, L. (2017). A two-stage decomposition method on fresh product distribution problem. International Journal of

Production Research, 1-24.

[55] Ivanov, D., Sokolov, B., Solovyeva, I., Dolgui, A., \& Jie, F. (2016). Dynamic recovery policies for time-critical supply chains under conditions of ripple effect. International Journal of Production Research, 54(23), 7245-7258.

[56] Jones, A. (2002). An environmental assessment of food supply chains: a case study on dessert apples. Environmental management, $30(4)$

$560-576$.

[57] Ketzenberg, M., Bloemhof, J., \& Gaukler, G. (2015). Managing Perishables with Time and Temperature History. Production and Operations Management, 24(1), 54-70.

[58] Krieter, J. (2002). Evaluation of different pig production systems including economic, welfare and environmental aspects. Archiv Fur Tierzucht-Archives of Animal Breeding, 45(3), 223-235.

[59] Kulak, M., Nemecek, T., Frossard, E., \& Gaillard, G. (2016). Eco-efficiency improvement by using integrative design and life cycle assessment. The case study of alternative bread supply chains in France. Journal of Cleaner Production, 112, $2452-2461$.

[60] Kusumastuti, R. D., Donk, D. P. v., \& Teunter, R. (2016). Crop-related harvesting and processing planning: a review. International Journal of Production Economics, 174, 76-92.

[61] Ladhari, R., \& Tchetgna, N. M. (2015). The influence of personal values on Fair Trade consumption. Journal of Cleaner Production, 87, 469-477.

[62] Lee, D., \& Tongarlak, M. H. (2017). Converting retail food waste into by-product. European Journal of Operational Research, 257(3), 944-956.

[63] Li, D., \& Wang, X. (2015). Dynamic supply chain decisions based on networked sensor data: an application in the chilled food retail chain. International Journal of Production Research, 1-15.

[64] Li, D., Wang, X., Chan, H. K., \& Manzini, R. (2014). Sustainable food supply chain management. International Journal of Production Economics, 152, 1-8.

[65] Lowe, T. J., \& Preckel, P. V. (2004). Decision technologies for agribusiness problems: A brief review of selected literature and a call for research. Manufacturing \& Service Operations Management, 6(3), 201-208.

[66] Maloni, M. J., \& Brown, M. E. (2006). Corporate social responsibility in the supply chain: an application in the food industry. Journal of business ethics, 68(1), 35-52.

[67] Manfredi, M., \& Vignali, G. (2014). Life cycle assessment of a packaged tomato puree: a comparison of environmental impacts produced by different life cycle phases. Journal of Cleaner Production, 73, 275-284.

[68] Manning, L., Baines, R. N., \& Chadd, S. A. (2006). Ethical modelling of the food supply chain. British Food Journal, 108(5), 358-370.

[69] Meneghetti, A., \& Monti, L. (2015). Greening the food supply chain: an optimisation model for sustainable design of refrigerated automated warehouses. International Journal of Production Research, 53(21), 6567-6587. 
[70] Meneses, M., Pasqualino, J., \& Castells, F. (2012). Environmental assessment of the milk life cycle: the effect of packaging selection and the variability of milk production data. Journal of Environmental Management, 107, 76-83.

[71] Miret, C., Chazara, P., Montastruc, L., Negny, S., \& Domenech, S. (2016). Design of bioethanol green supply chain: Comparison between first and second generation biomass concerning economic, environmental and social criteria. Computers \& Chemical Engineering, 85, 16-35.

[72] Mohan, S., Gopalakrishnan, M., \& Mizzi, P. J. (2013). Improving the efficiency of a non-profit supply chain for the food insecure. International Journal of Production Economics, 143(2), 248-255.

[73] Nakandala, D., Lau, H., \& Zhao, L. (2016). Development of a hybrid fresh food supply chain risk assessment model. International Journal of Production Research, 1-16.

[74] Nicholson, C. F., Gmez, M. I., \& Gao, O. H. (2011). The costs of increased localization for a multiple-product food supply chain: Dairy in the United States. Food Policy, 36(2), 300-310.

[75] Oglethorpe, D. (2010). Optimising economic, environmental, and social objectives: a goal-programming approach in the food sector. Environment and Planning A, 42(5), 1239-1254.

[76] Orgut, I. S., Ivy, J., Uzsoy, R., \& Wilson, J. R. (2016). Modeling for the equitable and effective distribution of donated food under capacity constraints. IIE Transactions, 48(3), 252-266.

[77] Parfitt, J., Barthel, M., Macnaughton, S., 2011. Food waste within food supply chains: quantification and potential for change to 2050. Philosophical Transactions of the Royal Society, B, 365, 3065-3081.

[78] Piramuthu, S., Farahani, P., \& Grunow, M. (2013). RFID-generated traceability for contaminated product recall in perishable food supply networks. European Journal of Operational Research, 225(2), 253-262.

[79] Piramuthu, S., \& Zhou, W. (2016). RFID and sensor network automation in the food industry: Ensuring quality and safety through supply chain visibility. John Wiley \& Sons.

[80] Resende-Filho, M. A., \& Hurley, T. M. (2012). Information asymmetry and traceability incentives for food safety. International Journal of

Production Economics, 139(2), 596-603.

[81] Rocco, C. D., \& Morabito, R. (2016). Robust optimisation approach applied to the analysis of production/logistics and crop planning in the tomato processing industry. International Journal of Production Research, 54(19), 5842-5861.

[82] Rodriguez, S. V., Pla, L. M., \& Faulin, J. (2014). New opportunities in operations research to improve pork supply chain efficiency. Annals of Operations Research, 219(1), 5-23.

[83] Rong, A., Akkerman, R., \& Grunow, M. (2011). An optimization approach for managing fresh food quality throughout the supply chain. International Journal of Production Economics, 131(1), 421-429.

[84] Rong, A., \& Grunow, M. (2010). A methodology for controlling dispersion in food production and distribution. Or Spectrum, 32(4), 957-978.

[85] Roy, P., Nei, D., Okadome, H., Nakamura, N., Orikasa, T., \& Shiina, T. (2008). Life cycle inventory analysis of fresh tomato distribution systems in Japan considering the quality aspect. Journal of Food Engineering, 86(2), 225-233.

[86] Schutz, P., Stougie, L., \& Tomasgard, A. (2008). Stochastic facility location with general long-run costs and convex short-run costs." 
[87] Seuring, S. (2013). A review of modeling approaches for sustainable supply chain management. Decision Support Systems, 54(4), 15131520.

[88] Sgarbossa, F., \& Russo, I. (2017). A proactive model in sustainable food supply chain: Insight from a case study. International Journal of

Production Economics, 183, 596-606.

[89] Sheu, J. B. (2016). Buyer Behavior in Quality-Dominated Multi-Sourcing Recyclable-Material Procurement of Green Supply Chains. Production and Operations Management, 25(3), 477-497.

[90] Shukla, M., \& Jharkharia, S. (2013). Agrifresh produce supply chain management: a state-of-the-art literature review. International Journal of Operations \& Production Management, 33(2), 114-158.

[91] Sodhi, M. S., \& Tang, C. S. Supply-chain research opportunities with the poor as suppliers or distributors in developing countries [J]. Production and Operations Management. 2014, 23(9): 1483-1494.

[92] Sonesson, U., \& Berlin, J. (2003). Environmental impact of future milk supply chains in Sweden: a scenario study. Journal of Cleaner Production, 11(3), 253-266.

[93] Soto-Silva, W. E., Nadal-Roig, E., Gonzlez-Araya, M. C., \& Pla-Aragones, L. M. (2016). Operational research models applied to the fresh fruit supply chain. European Journal of Operational Research, 251(2), 345-355.

[94] Soysal, M., Bloemhof-Ruwaard, J. M., \& van der Vorst, J. G. A. J. (2014). Modelling food logistics networks with emission considerations: The case of an international beef supply chain. International Journal of Production Economics, 152, 57-70.

[95] Soysal, M., Bloemhof-Ruwaard, J. M., Haijema, R., \& van der Vorst, J. (2015). Modeling an Inventory Routing Problem for perishable products with environmental considerations and demand uncertainty. International Journal of Production Economics, 164, 118-133.

[96] S"onmez, E., Lee, D., Gmez, M. I., \& Fan, X. (2016). Improving food bank gleaning operations: An application in New York State. American Journal of Agricultural Economics, 98(2), 549-563.

[97] Stringer, M. F., \& M. N. Hall (2007). A generic model of the integrated food supply chain to aid the investigation of food safety breakdowns. Food Control 18(7): 755-765.

[98] Tang, C. S., Sodhi, M. S., \& Formentini, M. (2016). An analysis of partially-guaranteed-price contracts between farmers and agri-food companies. European Journal of Operational Research, 254(3), 1063-1073.

[99] Tasca, A. L., Nessi, S., \& Rigamonti, L. (2017). Environmental sustainability of agri-food supply chains: An LCA comparison between two alternative forms of production and distribution of endive in northern Italy. Journal of Cleaner Production, 140, 725-741.

[100] Ting, S. L., Tse, Y. K., Ho, G. T. S., Chung, S. H., \& Pang, G. (2014). Mining logistics data to assure the quality in a sustainable food supply chain: A case in the red wine industry. International Journal of Production Economics, 152, 200-209.

[101] Tsao, Y. C. (2016). Designing a supply chain network for deteriorating inventory under preservation effort and trade credits. International Journal of Production Research, 54(13), 3837-3851.

[102] Brundtland, G. H. (1987). Report of the World Commission on environment and development:" our common future.". United Nations.

[103] Validi, S., Bhattacharya, A., \& Byrne, P. J. (2014). A case analysis of a sustainable food supply chain distribution systemA multi-objective approach. International Journal of Production Economics, 152, 71-87.

[104] van der Gaag, M., Vos, F., Saatkamp, H. W., van Boven, M., van Beek, P., \& Huirne, R. B. M. (2004). A state-transition simulation model for the spread of salmonella in the pork supply chain. European Journal of Operational Research, 156, 782-798. 
[105] van der Vorst, J. G. (2000). Effective food supply chains; generating, modelling and evaluating supply chain scenarios. sn].

[106] Van der Vorst, J. G. A. J., Tromp, S.C., \& van der Zee, D. J. (2009). Simulation modelling for food supply chain redesign; integrated decision making on product quality, sustainability and logistics. International Journal of Production Research, 47(23), 6611-6631.

[107] Vanek, F., \& Sun, Y. (2008). Transportation versus perishability in life cycle energy consumption: A case study of the temperaturecontrolled food product supply chain. Transportation Research Part D-Transport and Environment, 13(6), 383-391.

[108] Virtanen, Y., Kurppa, S., Saarinen, M., Katajajuuri, J. M., Usva, K., Menp, I., \& Nissinen, A. (2011). Carbon footprint of foodapproaches from national inputoutput statistics and a LCA of a food portion. Journal of Cleaner Production, 19(16), 1849-1856.

[109] Wang, X., Fan, Z. P., \& Liu, Z. (2016). Optimal markdown policy of perishable food under the consumer price fairness perception. International Journal of Production Research, 54(19), 5811-5828.

[110] Wang, X., Li, D., \&Obrien, C. (2009). Optimisation of traceability and operations planning: an integrated model for perishable food production. International Journal of Production Research, 47(11), 2865-2886.

[111] Wang, X., Li, D., \& Shi, X. (2012). A fuzzy model for aggregative food safety risk assessment in food supply chains. Production Planning \& Control, 23(5), 377-395.

[112] Webb, J., Williams, A. G., Hope, E., Evans, D., \& Moorhouse, E. (2013). Do foods imported into the UK have a greater environmental impact than the same foods produced within the UK? The International Journal of Life Cycle Assessment, 18(7), $1325-1343$.

[113] Raynolds, L. T. (2000). Re-embedding global agriculture: The international organic and fair trade movements. Agriculture and Human Values, 17(3), 297-309.

[114] Yakovleva, N., Sarkis, J., \& Sloan, T. (2012). Sustainable benchmarking of supply chains: the case of the food industry. International Journal of Production Research, 50(5), 1297-1317.

[115] Zanoni, S., \& Zavanella, L. (2012). Chilled or frozen, Decision strategies for sustainable food supply chains. International Journal of Production Economics, 140(2), 731-736.

[116] Zhang, W., \& Wilhelm, W. E. (2009). OR/MS decision support models for the specialty crops industry: a literature review. Annals of Operations Research, 190(1), 131-148. 